\title{
Measurement Science Needs for Real-time Control of Additive Manufacturing Powder Bed Fusion Processes
}

\author{
Mahesh Mani \\ Brandon Lane \\ Alkan Donmez \\ Shaw Feng \\ Shawn Moylan \\ Ronnie Fesperman
}

This publication is available free of charge from:

http://dx.doi.org/10.6028/NIST.IR.8036 


\title{
Measurement Science Needs for Real-time Control of Additive Manufacturing Powder Bed Fusion Processes
}

\author{
Mahesh Mani \\ Shaw Feng \\ Systems Integration Division \\ Engineering Laboratory \\ Brandon Lane \\ Alkan Donmez \\ Shawn Moylan \\ Ronnie Fesperman \\ Intelligent Systems Division \\ Engineering Laboratory
}

This publication is available free of charge from:

http://dx.doi.org/10.6028/NIST.IR.8036

February 2015

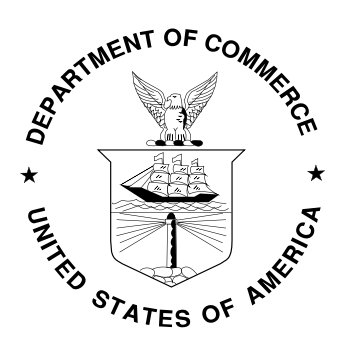

U.S. Department of Commerce

Penny Pritzker, Secretary

National Institute of Standards and Technology Willie E. May, Acting Under Secretary of Commerce for Standards and Technology and Director 


\section{Table of Contents}

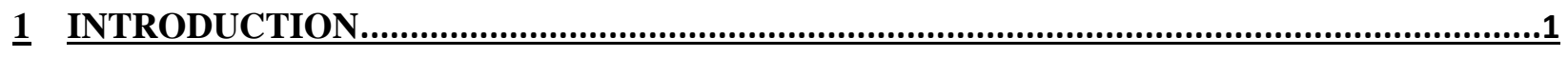

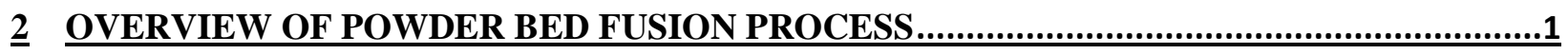

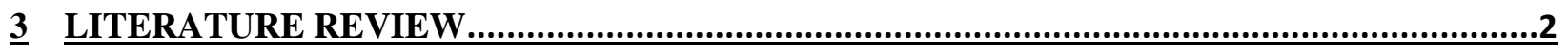

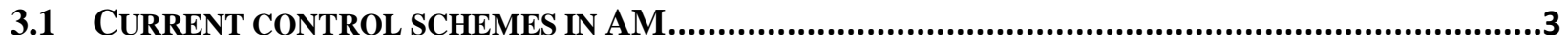

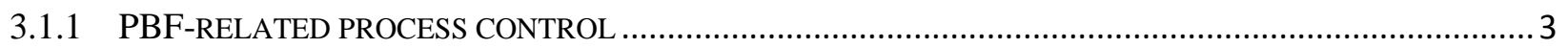

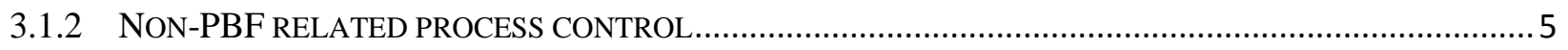

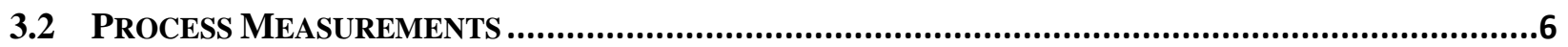

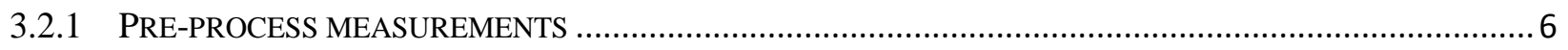

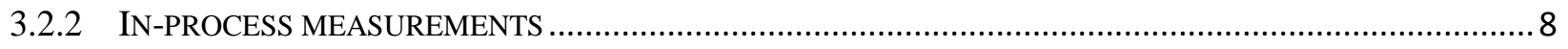

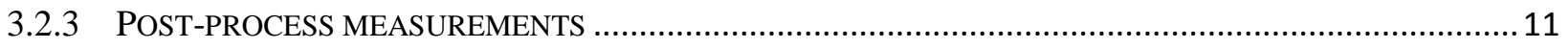

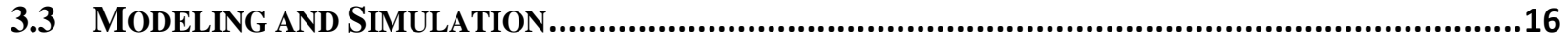

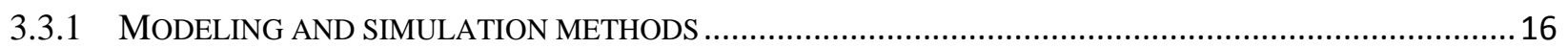

3.3.2 PARAMETER-SIGNATURE-QUALITY RELATIONSHIPS …......................................................... 17

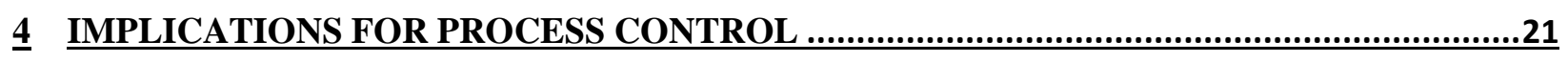

4.1 PARAMETERS-SIGNATURES-QUALITIES CATEGORIZATION ................................................21

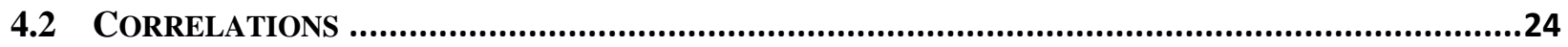

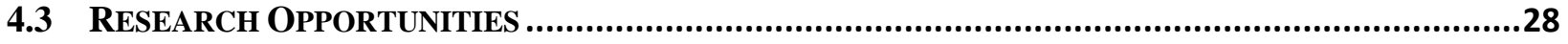

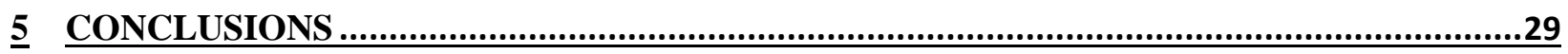

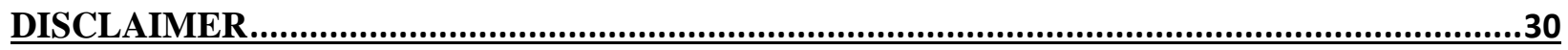

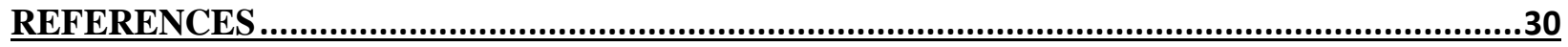

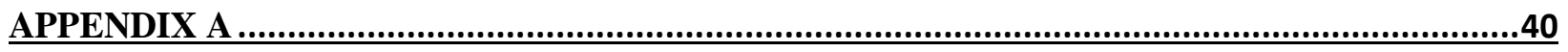


Abstract: Additive Manufacturing is increasingly used in the development of new products: from conceptual design to functional parts and tooling. However, today, variability in part quality due to inadequate dimensional tolerances, surface roughness, and defects, limits its broader acceptance for highvalue or mission-critical applications. While process control in general can limit this variability, it is impeded by a lack of adequate process measurement methods. Process control today is based on heuristics and experimental data, yielding limited improvement in part quality. The overall goal is to develop the measurement science ${ }^{1}$ necessary to make in-process measurement and real-time control possible in additive manufacturing. Traceable dimensional and thermal metrology methods must be developed for real-time closed-loop control of additive manufacturing processes. As a precursor, this report presents a review on the additive manufacturing control schemes, process measurements, and modeling and simulation methods as it applies to the powder bed fusion process, though results from other processes are reviewed where applicable. The aim of the review is to identify and summarize the measurement science needs that are critical to real-time process control. We organize our research findings to identify the correlations between process parameters, process signatures, and product quality. The intention of this report is to serve as a background reference and a go-to place for our work to identify the most suitable measurement methods and corresponding measurands for real-time control.

Keywords: additive manufacturing, powder bed fusion, real-time control, measurement science, correlations, process parameters, process signatures, product quality

\footnotetext{
1 Measurement science broadly includes: development of performance metrics, measurement and testing methods, predictive modeling and simulation tools, knowledge modeling, protocols, technical data, and reference materials and artifacts; conduct of inter-comparison studies and calibrations; evaluation of technologies, systems, and practices, including uncertainty analysis; development of the technical basis for standards, codes, and practices in many instances via test-beds, consortia, standards and codes development organizations, and/or other partnerships with industry and academia.
} 


\section{Introduction}

Additive manufacturing is increasingly used in the development of new products: from prototypes to functional parts and tooling. Additive manufacturing (AM) [1] is also referred to as rapid prototyping, additive fabrication, freeform fabrication, 3D printing, and rapid manufacturing, and uses advanced technologies to fabricate parts by joining and building up material layer-by-layer. According to [2] "the expected long-term impact is in highly customized manufacturing, where AM can be more cost-effective than traditional methods." According to an industry report by Wohlers Associates [3], by 2015 the sale of AM products and services could reach $\$ 3.7$ billion worldwide, and by 2019 , exceed $\$ 6.5$ billion. However, research is still required to fully realize the potential of AM, particularly for complex metal components (e.g., aerospace parts or automotive parts).

The widespread adoption of AM is challenged by part quality issues, such as dimensional and form errors, undesired porosity, delamination of layers, as well as poor or undefined material properties. Once the input material is established, part quality issues may be attributed to the AM process parameter settings, typically chosen today by a trial-and-error method. This approach is time consuming, inaccurate, and expensive. It is important to establish correlations between the AM process parameters and the process/part characteristics, to ensure desirable part quality and promote widespread adoption of AM technology. Once the correlations are established, in-process sensing and real-time control of AM process parameters can be done to minimize variations during the AM build process to ensure resulting product quality and production throughput.

According to a roadmap workshop on the measurement science needs for metal-based AM [4], [5] hosted by the National Institute of Standards and Technology (NIST), closed-loop control systems for AM was identified as an important technology and measurement challenge vital for: monitoring of process and equipment performance, assurance of part adherence to specifications, and the ability to qualify and certify parts and processes. Part quality in AM, defined by geometry, mechanical properties, and physical properties, is highly variable thereby limiting AM's broad acceptance. This variability can be reduced through robust process control.

Based on a literature review, the scope of this report is to identify the measurement science needs for realtime monitoring and control of powder bed fusion (PBF) processes. The report is subsequently organized as follows: Section 2 first presents an overview of the PBF process. Section 3 presents a literature review according to the review strategy to potentially identify the correlations between process parameters, process signatures, and product quality. Section 4 then presents the implications for real-time process control followed by a summary on the potential research opportunities. Section 5 concludes the report.

\section{Overview of powder bed fusion process}

Powder Bed Fusion (PBF) is one of the seven categories of AM processes defined in ASTM F2792 [1]. $\mathrm{PBF}$ processes use thermal energy to selectively fuse areas of a layer of powder using laser or an electron beam as the energy source [1]. When the energy source traces the geometry of an individual layer onto 
the top surface of the powder bed, the energy from the beam spot is absorbed by the exposed powder causing that powder to melt. This small molten area is often described as the melt-pool. Individual powder particles are fused together when the melt-pool re-solidifies. After one layer is completed, the build platform is lowered by the prescribed layer thickness, and a new layer of powder from the dispenser platform is swept over the build platform, filling the resulting gap and allowing a new layer to be built. Figure 1 depicts one such process that uses a laser beam as the energy source. When a part build is completed, it is fully buried within the powder in the build platform.

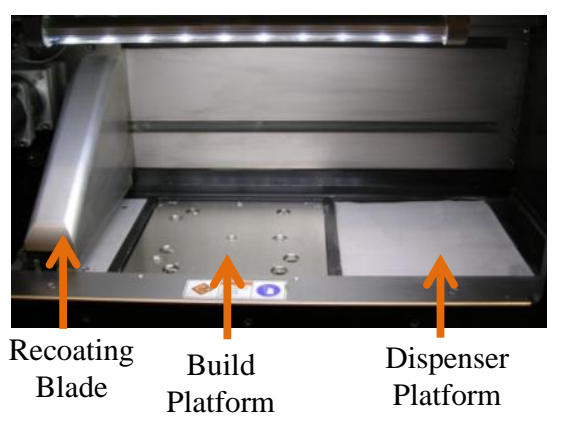

(a)

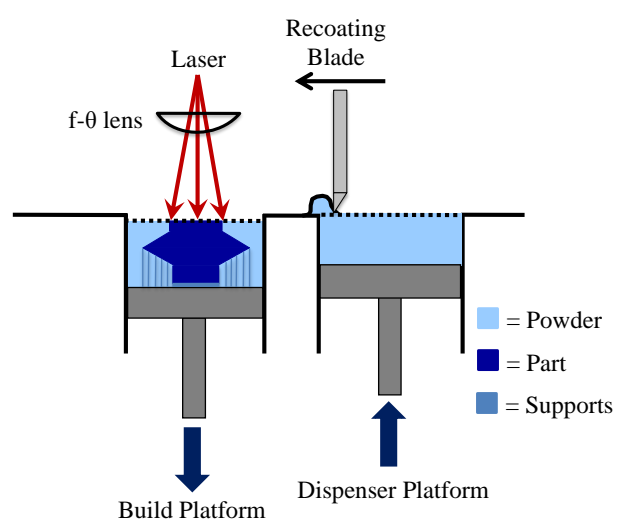

(b)

Figure 1. Components of the build chamber: (a) photograph showing the positions of the build platform, powder dispenser platform, and recoating blade, and (b) schematic depicting the process of recoating and spreading a new layer of powder over the previously fused layers of the part

There are several different types of PBF commercial systems that can produce either polymer or metal parts. Today, most of the commercially available metal-based AM systems are PBF processes [3]. Some varieties/ variations of PBF processes use low power lasers to bind powder particles by only melting the surface of the powder particles (called selective laser sintering or SLS) or a binder coating the powder particles. These processes produce green parts that require further post-processing to infiltrate and sinter the parts to make them fully dense. Another class of PBF processes uses high power energy beams to fully melt the powder particles, which then fuse together to the previous layer(s) when the molten material cools, e.g., selective laser melting (SLM), direct metal laser sintering (DMLS), or electron-beam melting (EBM). Repeating this process, layer-by-layer, directly results in a part with near $100 \%$ density, even in metals. These processes are of primary interest to this study. General specifications for metalbased PBF systems can be seen in the Appendix.

\section{Literature Review}

The central idea to the review strategy followed in this report is to identify the correlations between process parameters, process signatures, and product qualities to exploit these relationships in the monitoring and control solutions. AM process parameters are the 'inputs' and primarily determine the rate of energy delivered to the surface of the powder and how that energy interacts with material. We categorize process parameters into either controllable (i.e., possible to continuously modify), such as laser power and scan speed, or predefined (i.e., set at the beginning of each build) material properties, such as 
powder size and distribution. The process signatures are dynamic characteristics of the powder heating, melting, and solidification processes as they occur during the build. These are categorized into either observable (i.e., can be seen or measured), such as melt-pool shape and temperature, or derived (i.e., determined through analytical modeling or simulation), such as melt-pool depth and residual stress. Process signatures significantly influence the final product qualities. Those product qualities are categorized into geometrical, mechanical, and physical qualities. Identifying the correlations between process parameters, process signatures, and product qualities, as shown in Figure 2, should facilitate the development of the in-process sensing and real-time control of AM process parameters to characterize and control the AM PBF process.

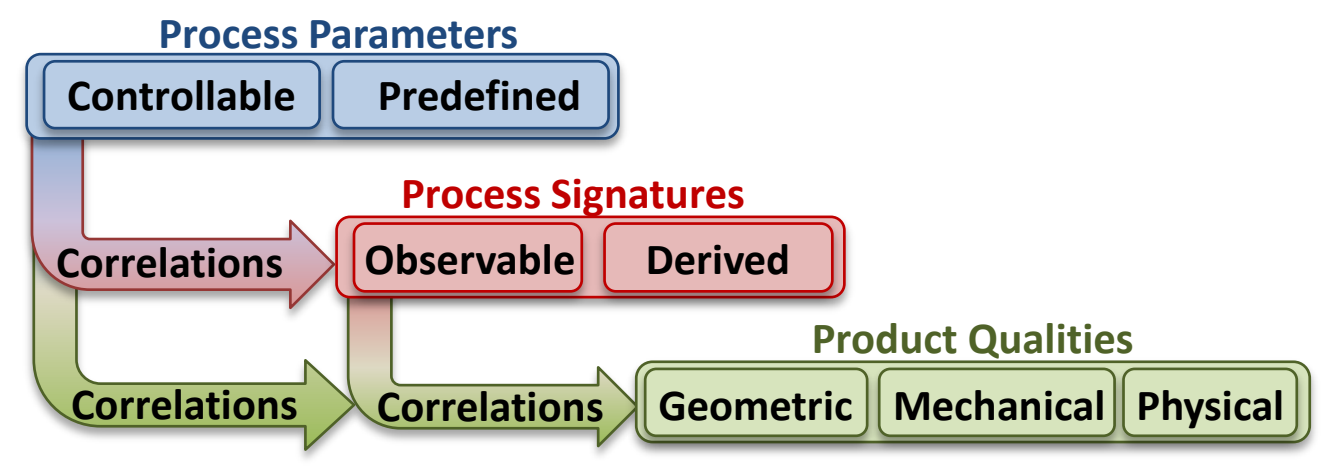

Figure 2. Correlations between process parameters, process signature and product qualities

We group the review into three categories: control schemes, process measurements, and modeling and simulation efforts as applicable to real-time process control.

\subsection{Current control schemes in AM}

This section reviews previous research efforts that are directly or potentially applicable to a closed-loop adaptive control system that utilizes melt-pool temperature and size, layer-by-layer part geometry, or defect characteristics as feedback.

\subsubsection{PBF-related process control}

In the reported studies, the melt-pool temperature and size are most often assumed to be the critical control factor influencing the outcome of the process.

The group at the Katholic University of Leuven developed a control system for a laser-based PBF system based on real-time monitoring of the melt-pool [6]. The melt-pool was monitored using a complementary metal-oxide semiconductor (CMOS) camera and a photodiode placed coaxially with the laser. The image from the camera was used to determine the melt-pool geometry. Based on their observation they found the photodiode signal correlated well with the melt-pool area. They used this area-based signature as feedback to control the laser power and showed improved surface roughness. Later, they extended their process control efforts by introducing an on-line control methodology using two complementary measurement systems: (1) visual inspection of powder deposition, and (2) real-time monitoring of meltpool, i.e., measuring both melt-pool geometry and infrared (IR) radiation intensity signal [7]. They state that the melting process is influenced by more than 50 parameters, which are classified as input 
parameters (such as scanning, deposition, and atmosphere) and boundary conditions (such as material properties, geometric parameters, machine parameters), and concede that monitoring or controlling all parameters is a significant challenge. This work extended their measurement system to include a visiblelight camera overlooking the entire build platform, which detected defects due to recoating blade wear as well as local damage of the blade. The same melt-pool monitoring system calculated melt-pool geometry (characterized as length-to-width ratio) in real-time. Results showed increasing photodiode intensities apparently due to defective layer-size control. This was attributed to overheating of the melt-pool during acute corners of the laser scan path. The optical system was further developed to detect process failures in each build layer by mapping the melt-pool temperature signatures as a function of the X-Y laser beam position on each layer [8]. Using such maps in real-time, the group was able to detect deformation due to thermal stresses and overheating zones due to overhangs.

Mumtaz and Hopkinson studied the effect of heat delivered to the melt-pool, i.e., the laser material interaction zone, to determine the roughness of the surface generated by the solidified melt-pool [9]. Heat affected zone (HAZ) is the area near and including the melt-pool that is directly affected by high local temperatures. Using a pulsed laser system, they experimented with various pulse shapes to distribute energy within a single laser pulse. It was proposed that the use of pulse shaping would offer precise and tailored control over the heat input and would allow refining and improvement over the use of standard rectangular pulses. The height of the laser-induced plasma plume was measured using a video camera to identify the correlation between the pulse shapes and the amount of spatter generated during processing. The added degree of control through pulse shaping resulted in a combined lower surface roughness on the top and side of the part.

Ning et al. studied the accuracy of a PBF system by investigating the percentage shrinkage due to different geometric shapes. They experimentally studied the effect of 2-D geometric shape factors on dimensional accuracy and later used that information to analyze the effect of different geometric shapes on the dimensional accuracy of the part. They regarded a change in the dimensional accuracy of the 2-D layer as a composite effect of the voxels. Each hatch vector (identified as a dexel) on a 2-D layer was used to denote a corresponding voxel. Based on this model, different geometric shapes can be regarded as different combinations of dexels. Analyzing the accuracy due to the effect of geometric shapes can be considered similar to analyzing the effect of the dexels and their interaction. Based on an empirical relationship, they developed a speed compensation method. The method involved controlling the scan speed and laser power separately or together for individual dexels to improve the accuracy of the fabricated parts [10]. Simchi, Petzoldt and Pohl reported on improving the accuracy of the sintered parts by using an integrated beam compensation technique, where the laser beam diameter is offset to compensate for the observed dimensional error as a result of the shrinkage. The process was strongly affected by shape, size, and distribution of the particles, and the chemical constituents of the powder. It was evident that the final part density strongly depends on the duration time of the laser beam on the surface of the powder particles. The study purported that by using optimized process parameters, such as scanning speed and scanning pattern accompanied by predefined powder characteristics such as particle size and distribution, high-density functional prototypes with superior mechanical properties can be produced. Further sintering behavior, mechanical properties, and microstructural features of the multicomponent iron-based powder were studied and presented [11]. Similar works based on laser beam offset were also reported in [12], [13]. 


\subsubsection{Non-PBF related process control}

Although the application of control systems specific for PBF processes in the literature is sparse, research on controlling other AM processes, notably in directed energy deposition (DED) processes, has been reported in the last two decades. DED processes use thermal energy to fuse materials by melting as they are being deposited [1].

Doumanidis and Kwak describe an optimized closed-loop control system (based on lumped parameter multi-input multi-output) for DED processes [14]. The control scheme is based on measuring bead profile geometry using a laser optical scanner and infrared (IR) pyrometry. The control involves modulating process input parameters, such as thermal source power, source velocity, material transfer rate, and direction of material transfer with respect to source velocity. Using analytical models based on mass, momentum and energy balance of melt-pool, as well as solid conduction in the substrate, they generated relationships between input parameters and the bead profile. A simplified proportional-integralderivative (PID) control system was implemented using the cross-sectional area of the bead as the scalar error (actual versus expected area) and the thermal source velocity as the input parameter. Due to practical limitations, the bead profile measurements are time delayed compared to process parameter inputs, which are handled by using a "Smith-predictor" scheme in the controller.

The control of melt-pool size under steady-state conditions over the full range of process variables was reported for a particular DED process (defined in this case as laser engineered net shaping, LENS) [14]. The control later extended to consider melt-pool size under transient conditions and as a function of process size scale [15]-[18]. Numerically determined melt-pool temperature response times were used to establish a lower bound on the response times for thermal feedback control systems. Similar works have been reported in [19].

Cohen developed a control system for droplet-based DED processes using the part geometry to determine the locations of subsequent droplets to compensate for geometric inaccuracies [20]. Using geometric measurements and a model of the target object, the system chooses appropriate locations for subsequent droplets such that the fabricated part ultimately matches the target geometry. The system chooses these deposition locations from a set of candidate locations by selecting 'best' candidates with the highest scores, as defined by a user-selected scoring algorithm.

Bi et al. investigated a closed-loop control of a DED process, based on the IR-temperature signal, for deposition of thin walls [21]. A PID controller was built between a photodiode and laser in the control system. The IR-radiation from the melt-pool was detected by the photodiode and converted to a temperature signal. The actual value of the temperature signal was compared with a set-value. The PIDcontroller created a control variable out of the deviation to regulate the laser power, so that the melt-pool temperature was controlled. The results showed that the process control with a path-dependent set-value could notably improve the homogeneity of the microstructure and hardness as well as the dimensional accuracy of the deposited samples.

$\mathrm{Hu}$ and Kovacevic studied real-time sensing and control to achieve a controllable powder delivery for the fabrication of functionally-graded material using DED processes [22]. An optoelectronic sensor was developed for sensing the powder delivery rate in real-time at a high sampling frequency. To achieve consistent processing quality, a closed-loop control system was developed for heat input control in the 
DED process based on the observed IR image of the HAZ. The experimental results of closed-loop controlled DED showed improvement in the geometrical accuracy of the part being built. A threedimensional finite element model was developed to explore the thermal behavior of the melt-pool. The results from the finite element thermal analysis were intended to provide guidance for the process parameter selection and an information base for further residual stress analysis [22][23].

Process maps have often been used as a method to optimize AM processes. For the DED processes, Birnbaum et al. considered the transient behavior of melt-pool size, due to a step change in laser power or velocity, for dynamic feedback control of melt-pool size using IR imaging techniques. They modeled the relationship between the process variables (laser power and velocity) and the desired melt-pool size [17]. They proposed a process map approach to condense results from a large number of simulations over the full range of process variables into plots process engineers could readily use. Bontha et al. addressed the ability of thermal process maps for predicting and controlling the microstructure in DED materials [24]. The focus of the work was the development of thermal process maps relating solidification cooling rate and thermal gradient (key parameters controlling microstructure) to DED process variables (laser power and velocity).

A closed-loop DED system with image feedback control was patented in 2002 [25]. The feedback controls material deposition using real-time analysis of IR radiation images. From the imaging data intrinsic parameters such as temperature distribution, size and shape of the molten pool, maximum degree of pool superheating, the trailing thermal gradient, and thickness of the deposition are extracted. A feedback-based control system then compares the current intrinsic parameters with the target intrinsic parameters to generate new control values (laser power and traverse velocity) based on the feedbackdriven adjustments and the predetermined operating schedule. The resulting system can fabricate components with a several-fold improvement in dimensional tolerances and surface finish.

The issue of residual stress control for laser-based AM processes has also been addressed using the process map approach [26], [27]. The thermal gradient behind the melt-pool was used to predict changes in residual stress based on thermal simulation results. A method of stress reduction by localized part preheating via a dual-beam laser or electron beam system was also proposed [28].

Table 1 in Appendix A summarizes the research efforts applicable to AM PBF control schemes.

\subsection{Process Measurements}

As mentioned previously, quality of the parts resulting from PBF processes varies significantly and depends on many interrelated influencing factors such as powder characteristics, process parameters, geometry, and other surrounding conditions. To clarify these relationships, researchers use a variety of measurement techniques. This section focuses on the pre-process, in-process, and post-process measurements described in literature to identify correlations (discussed in Section 4) between the key process parameters, process signatures, and product qualities.

\subsubsection{Pre-process measurements}

Pre-process measurements are generally not directly applicable to in-situ feedback control. However, they can potentially be used to define appropriate system input parameters, or supplement a process model for use in feed-forward control. They are also crucial to establishing relationships between input process 
parameters and process and part characteristics. These measurements often relate to material properties (density, thermal conductivity, etc.) and intrinsic properties of the system (laser power, powder absorptivity, etc.). Kruth et al. provided a list, based on a literature review, of additional material related properties that significantly affect melt-pool signatures: surface tension, viscosity, wetting, thermocapillary effects, evaporation, and oxidation [29].

Researchers at the National Institute of Standards and Technology (NIST) summarized metal powder characterization methods, in particular those that measure and describe powder size and distribution [30]. Another NIST study measured size distribution, particle morphology, chemistry, and density of powders and compared sample-to-sample consistency and variability from recycling of used metal powders [31]. Amado et al. also reviewed and demonstrated multiple methods of flowability characterization for polymer PBF powders for SLS applications [32]. While these works thoroughly described powder characterization techniques, they did not investigate the relationships between variations in these characteristics and resulting process signatures or final part quality.

The role of powder size and size distribution in sintering kinetics is well understood, i.e., it affects the relative density of the powder, which in turn affects the activation energy required for heated particles to coalesce [33], [34]. Smaller powder sizes with higher relative powder densities require less energy to sinter. It is known that a wider distribution of particles sizes can allow for higher powder density, since smaller particles can fit in the gaps between larger particles. McGeary demonstrated that specific ratios of bi-modally distributed powder sizes can achieve an optimal packing density of $84 \%$ with a 1:7 size ratio and a $30 \%$ weight fraction consisting of the smaller size [35]. Multimodal distributions could achieve even higher densities.

Higher relative density in powders improves the process by reducing internal stresses, part distortion, and final part porosity [29]. High relative densities increase the relative thermal conductivity of the powder bed [36], [37] (which is further discussed in Section 3.3). However, this decreases the absorptivity of the laser energy in AM systems, counteracting the benefits of a lowered energy barrier [38]. In some instances, these effects may negate each other. For example, Karlsson et al. measured little difference in hardness, elastic modulus, surface roughness, and macro and micro-structure in laser beam melting of Ti$6 \mathrm{Al}-4 \mathrm{~V}$ builds when comparing two powder size distributions of $25 \mu \mathrm{m}$ to $45 \mu \mathrm{m}$ and $45 \mu \mathrm{m}$ to $100 \mu \mathrm{m}$, [39]. Liu et al. also tested two powder distributions (narrow and wide with similar mean values) in the PBF process under varying scan speeds and laser power levels. They found that the wider particle size distribution, i.e., with a higher relative powder density, resulted in higher part density requiring less laser energy intensity [40]. Spierings et al. showed that unless a certain relative powder density is achieved, a lower scan speed (e.g., higher energy density) is required to produce fully dense parts [41], [42]. Differences in the relation of the powders to the densities, the layer thicknesses, and laser scan speeds indicate that powder grain size distribution should be taken into account for optimal results.

Further, local thermal conductivity has an effect on melt-pool signatures and thus part quality (see Section 3.3). Although metal powder thermal conductivity has been measured in multiple instances [43], conductivity of the fully dense material is generally better known and easier to measure. This measurement can be supplemented to models to derive the effective powder conductivity. Gusarov et al. demonstrated a method to calculate effective thermal conductivity of powders in which the relative 
density, the sphere packing coordination number (i.e., the mean number of the nearest neighbors to each particle), and the inter-particle contact size were shown to have the greatest effect [37].

Finally, there are certain pre-process measurements not involving input materials. For example, some part quality issues may stem from machine errors. These may include motion and positioning errors (with well-established measurement guidelines that may be taken from machine tool standards, e.g., ISO 2301), or errors in the laser optics and scanning system. These error sources and solutions for increased precision through better design or feedback control are not unique to AM, but relevant also to other manufacturing processes.

\subsubsection{In-process measurements}

The primary focus of research in in-process monitoring has been associated with determining the geometry and the temperature profile of the HAZ. IR thermography and pyrometry are two welldeveloped non-intrusive techniques for the measurement of surface temperatures. There is also some reported work on the in-process monitoring of the dimensional accuracy, errors, and defects during the build process. A few reports also discuss the in-process measurement of strain-stress.

\section{Surface Temperature measurement}

Thermographic imaging of AM processes can be grouped based on the optical path used by the imaging system. In co-axial systems, the imager field of view aligns with the laser beam through the beam scanning optics [8], [44]-[48]. In these systems, the field of view follows the melt-pool throughout its scan trajectory. Alternatively, the imager may be set externally to the build chamber to view the build through a window [49]-[53]. An improvised method was developed by Craeghs et al. [8]. Using the coaxial system, they mapped the charge-coupled device (CCD) camera and photo detector signals stemming from the melt-pool in the build plane using the XY laser scan coordinates. This created mapped images of the entire build area, with more local and detailed signatures of the melt-pool. Through this method, they could detect part deformation and overheating near overhanging structures through measured changes in the photo-detector signal. A lower signal resulted from the laser defocusing on distorted surfaces. A higher signal resulted on overhang surfaces that had less heat sinking support structure, and thereby poorer surface quality.

There are several known difficulties with thermography of additive processes. First and foremost, the imaged object's emissivity must be known in order to determine a true thermodynamic temperature from radiation-based measurements. Emissivity is likely different for the melt-pool, unconsolidated powder, and solidified surface, so a thermal image composed of all three components could give deceptive temperature predictions. For example, Rodriguez et al. noted that the powder areas surrounding the solidified part surfaces glowed brighter than the part in thermal images even though the powder was likely lower temperature [52]. This was attributed to the lower emissivity of the part surface, which reduced the imaged radiant intensity in these areas. Several techniques have been used to determine emissivity of different build components in AM systems: 1) assume a certain imaged area is at the liquidus or solidus temperature of the melt and use this as a reference emissivity [50], [51], [54], 2) create an emissivity reference by building and imaging a blackbody cavity [52], [55], or 3) only provide temperature without correction for emissivity (e.g., apparent or brightness temperature) or provide raw sensor signal values [56]. Another challenge, in particular with co-axial systems, is that f-theta lenses 
used in scanning systems induce chromatic or spectral aberrations. This requires that only radiation sensor systems with narrow bandwidth near that designed for the f-theta lens may be used accurately [8], [45], [57]. Finally, metallic debris from the HAZ can coat a window or viewport used in an AM imaging system, and disturb temperature measurements by changing the radiation transmission through the window [49], [51], [58]. This is particularly troublesome in electron-beam melting (EBM) systems, and prompted Dinwiddie et al. to create a system to continuously roll new kapton film over the viewport in order to provide new, unsullied transmission [49].

Several studies using thermography are of particular interest in relating process signatures to either input parameters or product qualities. Krauss et. al described the radiance (not temperature) images of the HAZ, captured by a micro-bolometer, in terms of area, circularity, and aspect ratio [56]. They compared these measurands versus scan speed, laser power, hatch distance, scan vector length, layer thickness, and changes when the melt-pool passes over an artificial flaw. Despite the relatively slow exposure time and limited resolution, they showed that size of the HAZ area was the most suitable measurand to detect deviations in scan velocity or laser power.

Yadroitsev et al. noted how melt-pool temperature, width, and depth in single track scans in selective laser melting (SLM) of Ti-6Al-4V increased with laser power and 'irradiance time', defined as the ratio of laser spot diameter to scanning speed [48]. Peak melt temperature increased with both power and irradiance time, but was more sensitive to power over the ranges measured. Melt-pool width and depth were measured from cross-sections cut from the melted tracks. They thoroughly characterized the microstructure of the SLM material for two scan strategies, and multiple post-build heat treatments. However, no definitive comparison of microstructure to the SLM process parameters or the thermal measurements was highlighted.

Hofmeister et al. empirically correlated cooling rate behind the melt-pool to the melt-pool size and noted how these changed depending on proximity to the build substrate and thus local average thermal conductivity in a LENS process [54]. They also noted calculating cooling rate is more difficult in a realtime monitoring system, and measuring melt-pool length as a corollary signature is more feasible. Similar to Yadroitsev et al. however, distinct correlations between thermographic process signatures to microstructure were not exemplified.

Santosprito et al. describe a thermography based system to record the movement of heat movement through the laser track [59]. Since defects (cracks, porosity, etc.) create lower conductivity regions and affect heat flow, they can be detected using thermography. However, since the changes due to these defects are small, they created new algorithms such as asymmetrical spatial derivative analysis, asymmetrical time derivative analysis, and asymmetrical line profile analysis (using multiple image frames and image subtraction) to improve the effectiveness of the defect detection. It was reported that a minimum defect size around $400 \mu \mathrm{m}$ is detectable with this system.

Dinwiddie et al. developed a high speed IR thermographic imaging system with an integration time of 1.0 $\mathrm{ms}$, retrofitted to a commercial electron beam machine, to monitor beam-powder interaction, quantify beam focus size, and detect porosity [60]. To overcome the contamination of the optics due to free metal ions released during the process, they designed a shutterless viewing system allowing continuous IR imaging of the beam-powder interaction. The paper describes the design of the system as well as examples of how to use this system in e-beam focus measurement (which requires spatial calibration), 
detection of over-melting during preheat, and porosity detection. However, since there was no temperature calibration, the images could not be converted to true temperatures. In another study, Dinwiddie et al integrated an extended range IR camera into a Fused Deposition Modeling (FDM) machine for imaging of the parts through the front window of the machine [61]. Another IR camera was integrated to the liquefier head to obtain higher resolution images of the extrusion process.

Price et al. described another implementation of near-IR (wavelengths in the range of $780 \mathrm{~nm}$ to $1080 \mathrm{~nm}$ ) thermography (with $60 \mathrm{~Hz}$ frame rate) for an EBM process [62]. They mounted the IR camera in front of the observation window of the machine and monitored the process as it goes through various stages, such as platform heating, powder preheating, contour melting, and hatch melting. They were able to measure the melt-pool size as well as the temperature profile across the melt-pool. However, they stated that the assumptions about the emissivity values are sources of uncertainty. The spatial resolution of the imaging system was reported as $12 \mu \mathrm{m}$ when using a close-up lens.

Pavlov et al. described pyrometric measurements taken co-axial with the laser to monitor the temperature of the laser impact zone to detect deviations of process signatures that correlate to deviations of process parameters from their set values [63]. This approach relies on the sensitivity of the temperature of HAZ with respect to process parameters. The laser impact zone surface temperature was measured using a bicolor pyrometer (1.26 $\mu \mathrm{m}$ and $1.4 \mu \mathrm{m}$ wavelengths with $100 \mathrm{~nm}$ bandwidth) covering a circular area of $560 \mu \mathrm{m}$ diameter with $50 \mathrm{~ms}$ sampling time. A laser spot size of $70 \mu \mathrm{m}$ diameter results in about a 100 $\mu \mathrm{m}$ re-melted powder track. A $400 \mu \mathrm{m}$ diameter optical fiber was used to collect temperature information. Temperature was represented as digital signal levels. Using this system, they investigated three strategies, namely: time variance of pyrometer signal during laser scanning of multiple tracks, changes in pyrometer signal as a function of hatch spacing (with thin and thick powder layers), and pyrometer signal changes as a function of layer thickness. The authors used this measurement method to differentiate the three process strategies proposed. They found that the pyrometer signal from the laser impact zone is sensitive to the variation of the main operational parameters (powder layer thickness, hatch distance between consecutive laser beam passes, scanning velocity, etc.), and could be used for on-line control of manufacturing quality [63]. Similar work was reported in [45].

\section{Residual Stress}

There are a number of techniques to measure strains and residual stresses in metal components. However, the relative part sizes and other physical attributes associated with the scanned region make it extremely difficult to apply direct methods of measurement. There are a number of reported indirect measurement techniques applicable. These indirect methods monitor physical attributes which are representative of the strains and residual stresses. Indirect techniques are based on strain or displacement measurement relating to the rebalancing of internal stresses that are released when material is removed or allowed to deform [64], [65].

Several researchers have reported on surface distortion measurement methods while investigating residual stresses [66]-[68]. Robert described a method that involves capturing the topography of the upper surface laser using a scanning confocal microscopy and deriving the platform's surface displacement by mapping the surface positions before and after the direct laser melting process [69]. Shiomi et al. discussed the use of strain gages mounted to the build platform to measure residual stress in-situ [70]. They were able to measure the strain changes in a build platform when SLS-induced layers were successively milled off. 
They found that the residual stresses decreased (i.e., stress relief) as more layers were removed from the built part.

More recently Van Belle et al. investigated residual stresses induced during a PBF process [71]. A strain gauge rosette was mounted under a support platform. By monitoring the variation of the strain gauge data, residual stress corresponding to elastic bending is calculated in the support and the part, using force balance principles.

\section{Geometric Measurements}

There is not much work that focuses on the in-process geometric measurements. Cooke and Moylan showed that process intermittent measurements can be viable for both process improvement and characterization of internal part geometries. Process intermittent measurements were compared to contact and non-contact measurements of the finished parts to characterize deviations in printed layer positions and changes in part dimensions resulting from post-process treatments [72].

Pedersen et al. [73] discussed a vision system for enhancing build-quality and as a means of geometrical verification. Given the very nature of layered manufacturing, a generic geometry reconstruction method was suggested, where each layer is inspected prior to addition of the successive layers. The hypothesis was that, although most AM processes have a tendency to accumulate stresses and suffer from elastic deformations, the non-deformed layers characterized by such systems will yield sufficient data to assess whether defects of internal geometries are present. This includes visually present defects from the inspected layers.

Kleszczynki et al. used a high resolution CCD camera with a tilt and shift lens to correct the image mounted on the observation window of a commercial PBF machine [74]. The camera has a field of view of $130 \mathrm{~mm} \times 114 \mathrm{~mm}$ with a pixel size of $5.5 \mu \mathrm{m} \times 5.5 \mu \mathrm{m}$. They categorized potential error sources during the build process and collected images representing these errors.

Table 2 in Appendix A summarizes the research efforts on in-process measurement.

\subsubsection{Post-process measurements}

The post-process measurements have in general focused on the part quality and are based on the following categories: dimensional accuracy, surface roughness, porosity, mechanical properties, residual stress, and fatigue. Parts, in the context of this review, consist of standard material testing specimens, process/design-specific specimens, and functional parts. This section captures relevant findings and correlations that have come from the post-process measurements.

\subsubsection{Dimensional accuracy}

Several papers discuss dimensional accuracy with examples. Yasa et al. investigated the elevated edges of parts, using a contact surface profilometer and optical microscope, built using different laser power levels, speeds, and scan strategies [75]. The paper identified that certain process parameters and scanning strategies could improve flatness of elevated surface. Abd-Elghany evaluated PBF processed parts with low-cost powders by measuring dimensions before and after finishing by shot-peening process. Using a $3 \mathrm{D}$ scanner it was observed that the part was $2 \%$ to $4 \%$ larger than designed before shot peening, and 1.5 $\%$ after. It was also noted that the tolerances were not uniform and varied in the z-direction [76]. Mahesh 
et al. investigated the controllable and uncontrollable parameters in a PBF process [13]. They identified correlation between the controllable process parameters such as scanning speed, laser power, and scanning direction on the geometrical profiles of the geometric benchmark part. They reported the preferred settings of control parameters based on the analysis of the mean dimensional errors for the specific geometric features on the benchmark part. Paul and Anand developed a mathematical analysis of the laser energy required for manufacturing a simple part based on laser energy expenditure (minimum total area for sintering) of SLS process and its correlation to the geometry [77]. Khaing et al. studied the design of metal parts fabricated by PBF [78]. A coordinate measuring machine (CMM) was used to measure the dimensional accuracy of the parts. They observed deviations along the $\mathrm{X}$ and the $\mathrm{Y}$-axis. The values along the $\mathrm{Y}$-axis were the most accurate. They concluded that the optimization of the process parameters and the accuracy of the laser scanning units were crucial to improve the dimensional accuracy. Krol et al. studied the prioritization of process parameters for an efficient optimization of AM by means of a finite element method. They stated that the scanning speed, the support geometry, the preheating temperature of the substrate, and the scanning pattern were the most influential parameters for dimensional accuracy [79]. Similarly Delgado et al. [80] and Wang et al. [81] also reported on the influence of process parameters on part quality. Table 3 in Appendix A summarizes the related research on dimensional accuracy as it applies to part quality.

\subsubsection{Surface quality}

Abd-Elghany and Bourell evaluated the surface finish of the PBF processed part with layer thickness of $30 \mu \mathrm{m}, 50 \mu \mathrm{m}$, and $70 \mu \mathrm{m}$. The roughness of the top and side surfaces was measured using a scanning electron microscopy (SEM), equipped with an energy dispersive X-ray (EDX) analyzer. The results of this study indicated that large particles inside thick layers could increase surface roughness because the volume of particles have a tendency to form voids when they are removed in finishing processes. It was also noted that the side surface was smoother at the bottom than at the top [76]. Mumtaz and Hopkinson investigated the laser pulse shaping on thin walls of parts built by PBF by relating pulse shape, thin-wall width, and plasma plume height to surface roughness using a profilometer, digital calipers, and digital video camera. The results of this study indicated that the wall width varied with the pulse shape, which in turn influenced the melt-pool width. A suppressed pulse shape that consisted of a high peak power, low energy, and short time duration proved to be the most effective pulse shape for PBF [9]. Meier and Haberland investigated various process parameters to evaluate their influence on part density and surface quality for parts fabricated by PBF [82]. Approaches to improve density, surface quality, and mechanical properties were also presented. Related research was also reported in [42], [75], [80]. Table 4 in Appendix A summarizes the related research on surface quality.

\subsubsection{Mechanical properties}

Meier and Haberland investigated failures in tensile tests of stainless steel and cobalt-chromium parts. The findings showed that the density measurements do not identify deficient connections of consecutive layers, and vertically fabricated specimens have lower tensile strengths and elongations [82]. AbdElghany and Bourell also characterized hardness and strength as a function of layer thickness and scan speed using hardness, tensile, and compression tests for SLM process. The findings conclude that hardness is not much affected within the range of process parameters studied; however, variations in hardness due to surface porosity were observed. Strength was good at low scanning speeds and thin layers. The parts became brittle with higher layer thickness due to porosity and micro-cracking. 
Compression testing resulted in shapes identical to the buckling of solid parts, i.e., layers were very coherent and did not separate or slip due to secondary shear forces [76]. Sehrt and Witt investigated a dynamic strength and fracture toughness on a cylindrical beam and disk by the rotating bending fatigue tests. Specimens were investigated at defined oscillating stresses and the resulting number of cycles that led to the failure of the specimen was determined. The findings showed that fatigue strength was comparable to conventionally manufactured parts [83]. Storch et al. [84] analyzed material properties of sintered metals to qualify metal-based powder systems in comparison to conventional materials used in automotive engines and power trains. Key observations included material properties being sensitive to the build direction and that material strength increases with the chamber atmospheric temperature.

By studying the material properties and the process parameters, Gibson and Shi concluded that the powder properties directly affect the process, which in turn affect the mechanical properties of the resultant component [85]. The research concluded that the knowledge of the effects of sintering and postprocesses must be incorporated into design and post processing.

Wegner and Witt developed a statistical analysis to correlate part properties with main influencing factors. According to their study, PBF shows non-linear correlations among multiple parameter interactions. The four main influences on mechanical properties (i.e., tensile strength, Young's modulus, elongation) were scan spacing, scan speed, layer thickness, and interaction of scan spacing and layer thickness [86].

Manfredi et al. reported on the characterization of aluminum alloy in terms of size, morphology, and chemical composition, through the measurement and evaluation of mechanical and microstructural properties of specimens built along different orientations parallel and perpendicular to the powder deposition plane [87].

Yadroitsev and Smurov studied the effects of the processing parameters such as scanning speed and laser power on single laser-melted track formation. Experiments were carried out at different laser power densities ( 0.3 parameter ${ }^{6} \mathrm{~W} / \mathrm{cm}^{2}$ by continuous wave $\mathrm{Yb}$-fiber laser. Optimal ratio between laser power and scanning speed (process map) for $50 \mu \mathrm{f}$ layer thickness was determined for various stainless steel grade material powders. A considerable negative correlation is found between the thermal conductivity of bulk material and the range of optimal scanning speed for the continuous single track sintering [88].

Related research was also reported in [42], [80], [89]- [90].

Table 5 in Appendix A summarizes the related research on mechanical properties.

\subsubsection{Residual stress}

With rapid heating and cooling inherent in any PBF process, especially in a process that fully melts metal powder, thermal stress and residual stress certainly affect the resulting parts. These residual stresses are most apparent when they cause warping of the part, features, or build platform. As such, residual stress has been widely studied by AM researchers [69]- [71], [90]- [102]. Mercelis and Kruth described the two mechanisms causing the residual stress: the large thermal gradients that result around the laser spot and the restricted contraction during the cooling that occurs when the laser spot leaves the area [96]. Withers and Bhadeshia discussed the techniques used to measure residual stress, and most of these methods are performed post-process and often require some sort of specimen destruction [100]. The 
methods include hole drilling (distortion caused by stress relaxation), curvature (distortion as stresses rise or relax), x-ray diffraction (atomic strain gauge), neutrons (atomic strain gauge), ultrasonics (stress related changes in elastic wave velocity), magnetic (variation in magnetic domains with stress), and Raman spectroscopy. Shiomi discussed the use of strain guages mounted to the build platform to measure residual stress in-situ [70]. Van Belle et al. expanded upon this method, using a table support mounted to the bottom of the build platform [71]. The table support was designed to amplify strain and was instrumented with strain gages to measure that strain. A thermocouple was also mounted close to the strain gauge to record the temperature evolution for the thermal strain. The removed layer method was used and modified to determine the residual stress in the part and the support during the layer addition with the measured strains.

It was observed that many researchers linked process parameters to the residual stress present in the resulting parts and investigated strategies to reduce the residual stresses. The most commonly discussed method of reducing residual stress was through post process heat treatment [93], [99], [70], [96], although these results have little impact on process control. Residual stresses were also significantly reduced by heating the build platform [70], [96], i.e., higher heating temperatures resulting in lower residual stresses. The path the laser beam follows to trace and fill the geometry (i.e., scan strategy) of each layer has also been shown to influence the residual stress present [96], as well as the layer thickness used to build the part [71], [94]. Table 6 in Appendix A summarizes the related research on residual stress as it applies to part quality.

\subsubsection{Porosity/Density}

The effects of various process parameters on part density for many materials have been investigated and the contributors causing porosity have been identified. Laser power, scan speed, scan spacing, and layer thickness can be directly related to energy density and thus to part density. Several researchers have studied the effects of energy density parameters on different materials like 316L stainless steel [41], [82], [103], [104], 17-4 Precipitation Hardening (PH) steel [105], Ti6Al4V [104], and American Iron and Steel Institute (AISI)-630 steel [105]. Their efforts suggest a correlation between the energy density and the part density. Parthasarathy evaluated the effects of powder particle size, shape, and distribution on the porosity of 316L stainless steel [106]. Porosity/density has a direct effect on the mechanical properties of components fabricated by PBF [107]. Internal and external pores, voids, and micro-cracks introduced during fabrication act as stress concentrators that cause premature failure and thus compromising part quality. Fully dense parts (100\% relative density), however, have shown to have mechanical properties equal to or better than the properties of wrought materials.

Morgan et al. investigated the effects of re-melting on the density of the part [103]. The density increased with decreasing scan speed. Density decreases with decreasing scan spacing but not significantly. The plasma recoil compression forces can modify melt-pool shape and affect density. There appeared to be a maximum energy density associated with part density. Gu et al. studied the influences of energy density on porosity and microstructure of PBF 17-4PH stainless steel parts [108]. They showed that coupons fabricated using the same energy density level using different laser powers and scan speeds showed significantly different levels of porosity. Two types of porosity formation mechanisms were identified and discussed. Balling phenomena and high thermal stress cracking were mainly responsible for the porosity that occurs at very high laser power and scan speed, while insufficient melting is the primary reason for crevices filled with many un-melted powders at very low laser power and scan speed. Also, pores in 
coupons manufactured using both high laser power and scan speed exhibit smaller size and more circular shape in comparison with pores in coupons manufactured using both low laser power and scan speed.

Chartterjee et al. investigated the effects of the variation of sintering parameters: layer thickness and hatching distance on the density, hardness, and porosity of the sintered products [109]. Applying statistical design of experiments and regression analysis, they observed that the increasing layer thickness and hatching distance results in an increase in porosity that diminishes the hardness and density.

Related research was also reported in [42], [76], [80], [89], [110]- [111].

Table 7 in Appendix A summarizes the related research on porosity and density as it applies to part quality.

\subsubsection{Fatigue}

Fatigue performance is crucial if AM parts are to be used as functional components in dynamic environments, e.g., aircraft engines. Under dynamic conditions, AM parts have shown to have a high sensitivity to surface quality and internal pores that act as stress risers. Researchers have recently reported on studies to characterize fatigue performance, endurance limit, and fracture behavior of AM components for various materials that include 15-5PH, 17-4PH, 316L stainless steel, AlSi10Mg, Ti6Al4V, and CPG2Ti [42], [83], [93], [108], [112]-[116]. Sehrt and Witt [83] investigated the dynamic strength and fracture toughness of $17-4 \mathrm{PH}$ stainless steel components using Woehler fatigue tests (i.e., rotating bending test) and compact tension tests [ASTM E399, DIN EN ISO 1237]. They found that the fatigue strength and the critical stress intensity factor for additively manufactured 17-4PH components are comparable to conventionally-manufactured components. Other researchers performed high cycle fatigue (HCF) tests described by ASTM E466 [93], [112], [113], [115]. Leuders et al., studied the effects of heat treatment and hot isostatic pressing (HIP) for vertically built specimens and found that fatigue life increased with increasing temperature [93]. By closing near surface pores, HIP was found to increase the fatigue life of Ti6Al4V to a level above two million cycles. In addition to evaluating the fatigue of vertically built Ti6Al4V specimens, Rafi et al., also evaluated 15-5PH specimens [117]. Titanium alloy Ti6A14V and $15-5 \mathrm{PH}$ specimens were heat treated at $650^{\circ} \mathrm{C}$ for four hours and at $482^{\circ} \mathrm{C}$ for precipitation hardening, respectively. Their results suggested that the fatigue life of PBF Ti6A14V specimens is better than cast and annealed specimens. However, the endurance limit of $15-5 \mathrm{PH}$ was reduced by $20 \%$ when compared to conventionally-manufactured components. Spierings et al. compared the endurance limit for as-built, machined, and polished specimens [108]. Like Rafi et al., they also reported that the endurance limit for $15-5 \mathrm{PH}$ was reduced by $20 \%$. Similarly, the endurance limit for $316 \mathrm{~L}$ was reduced by $25 \%$ when compared to conventionally manufactured components. Spierings et al., also reported that as-built specimens were weakest and polished specimens were only slightly better than machined [115]. Brandl et al., studied the effects of heat treatment and vertical build orientation on the HCF performance of AlSi10Mg samples. The authors concluded that a combination of heat treatment $\left(300{ }^{\circ} \mathrm{C}\right)$ and peakhardness increases fatigue resistance and neutralizes the effects of build orientation. Additionally, the fatigue resistance of PBF AlSi10Mg samples was very high when compared to standard cast samples [112]. To further investigate the practicality of using SLM components as functional parts, Spierings et al. 2011, successfully designed, fabricated, and tested brackets used for supporting the suspension of a formula race car [42]. Table 8 in Appendix A summarizes the related research on fatigue as it applies to part quality. 


\subsection{Modeling and Simulation}

Science-based predictive models are crucial to predict the material behavior that accounts for the changes in material properties. Detailed understanding of material changes during melting (microstructural changes, phase transformations) would enable optimization and control of the processes improving overall product quality. Such capabilities integrated into the current control schemes can potentially cater to much desired feed forward and feedback capabilities. Many models have been developed for simulating highly dynamic and complex heating, melting, and solidification of materials during PBF processes. Dynamics imply heating, melting, wetting, shrinking, balling, solidification, cracking, warping, etc. in a very short period of time. Complexity implies highly coupled heat and metallurgical interactions in the AM process. This section provides a literature review of available modeling and simulation research works with the following objectives: 1) evaluate currently available physics-based, numerical models that describe the PBF processes; and 2) investigate observable and derived process signatures that are necessary for closed-loop control.

Zeng, Pal, and Stucker [118] thoroughly reviewed the development and methodology in modeling and simulation research for PBF processes. Therefore, construction of the numerical models is only briefly reviewed here with select examples highlighted. Though much focus of AM modeling papers is on development and model verification, many offer insight into process parameter relationships. The use of modeling to guide process control development is not limited by the models, but by the focus of the modeling efforts. Here, we attempt to extract what information from modeling and simulations may be utilized in control schemes, and identify those derived process signatures that require modeling and simulation if they hope to be controlled.

\subsubsection{Modeling and simulation methods}

Nearly all models of the PBF and DED processes include the following input parameters in one form or another: 1) a heat source representing the laser with associated power and profile shape and 2) a body of powder with associated geometry, boundary conditions (typically radiation and convective top surface with either adiabatic or isothermal bottom surface), and thermo-mechanical material properties. These are modeled either numerically (e.g., through multi-physical finite element analysis) or analytically with varying degrees of dimension, geometry, scale, and with varying modeled phenomena or sub-processes. In three dimensional (3D) finite element models, laser heat sources are typically modeled as a Gaussianshaped surface flux with variable power or radius, or as an internal heat generation [119]. Many use a laser 'absorptance' factor relating the fraction of laser energy converted to thermal energy, and/or an 'extinction coefficient' or 'penetration depth' of the laser energy into the powder. Gusarov et al., developed an analytical model for absorptance, extinction coefficient, and reflected radiation based on multiple laser reflections and scattering through the open pores of a powder bed [38], [120]. Various other empirical or analytical sub-models are also used for temperature, phase, or powder densitydependent thermal conductivity and specific heat [119], [121]-[125].

Analytical models mostly use the 3D "Rosenthal" solution for a moving point heat source [126]. However, its limited complexity allows it only to verify more complex results from numerical methods (e.g., finite element (FE) results from [127]). Other, more complicated analytical models typically use numerical methods such as finite difference to solve for laser radiation interactions [128]. 
Some analytical models use non-dimensional parameters, which aid in comparison of models and experiments across varying scales and conditions. Vasinonta et al. developed non-dimensional parameters that relate input parameters and results of DED process simulations to material parameters based on the Rosenthal solution [26], [129]. Others who develop non-dimensional parameters include Chen and Zhang [130], [131] for the SLS process, and Gusarov et al., described results using traditional heattransfer non-dimensional parameters such as Peclet number using the laser beam width as a characteristic length [132]. For a more thorough analysis of potential non-dimensionalized parameters for the PBF process, see [133].

A relatively new method for modeling hydrodynamic effects in the melt-pool is the lattice Boltzmann method (LBM). This method uses particle collision instead of Navier-Stokes equations in fluid dynamics problems. The LBM can model physical phenomena that challenge continuum methods, e.g., influence of the relative powder density, the stochastic effect of a randomly packed powder bed, capillary and wetting phenomena, and other hydrodynamic phenomena [134]. For example, Korner et al. demonstrated multiple melt-pool morphologies could result from the stochastically varying local powder density near the scanned region, or effect of changing the bulk powder density. They also developed a process map for scan morphology as a function of laser speed and power for one specified powder packing density. LBM is very computationally intensive, since multiple simulations are needed (by varying input parameters) to extract parameter-signature relationships. For further reference on LBM methods in AM, see [134]-[137].

\subsubsection{Parameter-Signature-Quality Relationships}

In general, for single scan tracks in powder-bed type processes, the melt-pool and high temperature zone form a comet-like shape, with a high temperature gradient in the leading edge of the melt-pool, and lower temperature on the trailing edge [36], [122], [138], similar to results from Hussein et al. in Figure 3.

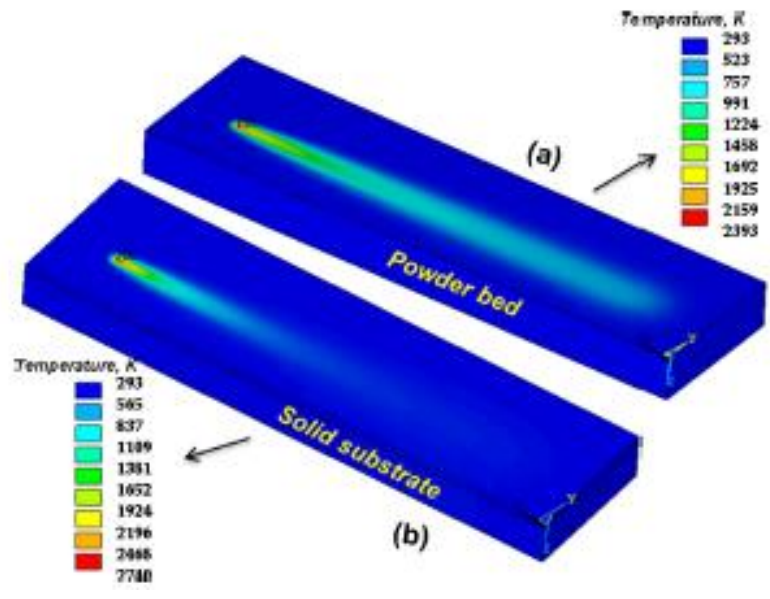

Figure 3. FE simulation surface temperature results showing comet-like shape, and the temperature distribution's relation to proximity to high conductive zones (e.g., solid substrate, image (b)) or low conductive zones (e.g., powder bed). Image from Hussein et. al. [138].

As mentioned earlier, melt-pool size and temperature are already being used as feedback parameters in closed-loop control schemes. Melt-pool size as a single-valued measurand is not always defined explicitly in reported simulation results. This is likely due to the fact that full characterization of the melt-pool throughout its volume is possible, and single-value measurands are found to be too simplistic. However, 
length (in the scan direction), depth, width, and area values are sometimes used to relate to process parameters. Often in AM modeling literature, a plot of the melt-pool temperature vs. some cross-section distance is given [119], [138]-[140]. Melt-pool size may be inferred and related to input parameters, though it is not often expressed as a single-value measurand (e.g., the melt-pool is x mm). Soylemez et al., mentioned that while melt-pool cross-sectional area is a key descriptor, melt-pool length was known to affect deposited bead shape, so they proposed using length-to-depth ratio (L/d) as a descriptor in their process mapping efforts [141]. Childs et al., also mentioned that L/d ratio determined the boundary between continuous and balled tracks when scanning on powder beds without a solid substrate [142].

Typically, the melt-pool size and temperature increase with laser power, however the relationship with scan speed is more complicated. For stationary pulsed laser tests (e.g., [143], the effects of longer pulse durations are related to lower scan speeds and resulting higher temperature. Multiple simulation efforts have addressed the trends in temperature and size of the melt-pool with process parameters, which are organized in Table 9. It was shown in [138] that the width and depth decreased slightly with scan speed (from $100 \mathrm{~mm} / \mathrm{s}$ to $300 \mathrm{~mm} / \mathrm{s}$ ), while the length of the melt-pool in the scan direction increased, contributing more to the overall melt-pool size. This was for the single-layer model geometry shown in Figure 3. Chen and Zhang also showed depth decreasing with speed, but change in length was less pronounced [130]. Chen and Zhang also created simulations where melt-pool depth was kept constant, which required more input power at the higher speeds. The thin-wall geometry modeled in [26], [27] (not PBF) showed that melt-pool length decreased with increasing scan speed, though at much lower speeds $(<10 \mathrm{~mm} / \mathrm{s})$. One interesting approach by Birnbaum et al., used a finite element model to look at transient changes to melt-pool geometry given a step change in laser power with the specified intent to apply in thermal imaging feedback control [17].

Table 9. Commonly observed melt-pool signatures and related process parameters evidenced in AM models and simulations

\begin{tabular}{|c|c|c|c|}
\hline $\begin{array}{l}\text { Melt-pool } \\
\text { Signature }\end{array}$ & Relationship & Measurand & References \\
\hline \multirow{3}{*}{$\begin{array}{l}\text { Temperature } \\
\text { (peak) }\end{array}$} & Increases & Laser power & [119], [139], [140], [143]-[145] \\
\hline & Decreases & Scan speed & {$[138],[139],[144]-[146]$} \\
\hline & Decreases & Thermal conductivity* & {$[138],[142]$} \\
\hline \multirow[t]{5}{*}{ Size $^{* *}$} & $\begin{array}{l}\text { Length, width, and } \\
\text { depth increase }\end{array}$ & Laser power & $\begin{array}{l}{[26],[36],[119],[130],[139],} \\
{[140],[143]-[145]}\end{array}$ \\
\hline & Width - decrease & Scan speed & [132], [138], [144] \\
\hline & Length - increase & Scan speed & [132], [138] \\
\hline & Depth-decrease & Scan Speed & {$[36],[130],[132],[138],[145]$} \\
\hline & $\begin{array}{l}\text { Length, width, and } \\
\text { depth increase }\end{array}$ & Thermal conductivity* & [138], [142], [145] \\
\hline
\end{tabular}

Modeling offers a comprehensive analysis of the melt-pool, to deduce the irregular shape and temperature contours in the interior and not just the surface. Surface level measurements of melt-pool signatures are 
leading efforts in in-situ process control. Modeling and simulation can relate these melt-pool signatures to the complex and dynamic characteristics internal to the melt-pool, powder bed, or the solid part itself, such as residual stresses, porosity, or metallic phase structure.

One promising application of AM simulation to closed-loop control is the ability to study the effect of variable thermal conductivity on melt-pool signatures, and thus the part quality. The fully solidified part exhibits higher thermal conductivity than the surrounding powder, thereby conducting more heat from the laser source, reducing the melt-pool temperature but increasing its size. Multiple AM models have shown this phenomenon or studied it in detail [130], [138], [142]. Hussein et al., showed how the melt-pool and trailing hot zone changed temperature and shape depending on whether the laser scanned over powder bed (low thermal conductivity) or solid substrate (high conductivity) [138]. Scanning over the powder bed produced lower peak temperatures in the melt-pool but higher temperatures in the trailing region for the first scan. However, this trend changed such that subsequent scans over the solid substrate always resulted in lower temperatures. Chen and Zhang simulated multiple layers while keeping melt-pool depth constant [130]. They showed that more power was necessary as build layers increased to maintain the processing depth, indicating that more heat was conducting into the solid layers. Wang came to the same conclusion, but for multiple layers in a thin-wall geometry [123]. The relationships between melt-pool signatures and changes in thermal conductivity have guided the use of feedback controlled melt-pool size. However, there are other critical phenomena that are less understood, but may be addressed through intelligent melt-pool monitoring guided by results from modeling and simulations.

The time-history of temperature plays a crucial role in residual stresses and build-direction variability in density and material phase structure. While extremely important to final part quality, these phenomena are difficult to measure in-situ during a build. In the future, successful models may be able to predict these phenomena to be exploited in feed-forward control schemes. In a series of papers, Wang et al. [123], [124] looked at time history of temperature in each layer as the build progresses in a DED system. Subsequent scans on new layers re-heated the base layers, which turned originally hard martensitic layers to softer, tempered martensite while new layers stayed consistently hard. By increasing scan speed and laser power (keeping melt-pool size constant), the number and consistency of hard, martensitic layers could be increased since the lower layers were subjected to shorter heating from upper layer builds. Others have studied this lower layer reheating phenomena [122], [139] and its effect on residual stresses [138], [147]-[149].

Others [138], [140], [144] also studied pre-heating and post-heating of a surface point before and after the laser scan had passed on one layer (rather than subsequent layers). Under certain conditions, locations on previously scanned tracks were re-melted. This number of re-melting cycles increases for narrower hatch spacing. For constant hatch spacing, Yin et al., showed that lower scan speeds promoted re-melting primarily due to the resulting higher temperatures [140]. However, one can assume that under different conditions, a slower scan speed would allow points on adjacent tracks to cool enough not to be re-melted. This re-melting effect has been shown experimentally to relate to part quality (e.g., surface roughness, mechanical properties, porosity) [150].

Hussein et al., also studied thermal stresses in powder bed geometry for multiple layers [138]. Their results showed that regions in the build experience thermal expansion and contraction based on the local temperature history and build geometry. It was also demonstrated that the relationships between the melt- 
pool signatures and residual stresses are very complex; therefore melt-pool monitoring may not provide enough information to predict residual stress formation. Nickel et al., specifically investigated effects of scanning pattern on residual stress and part deformation [151]. Though this forms an excellent guide to optimal scanning patterns developed before the build takes place, it is unlikely that scan patterns can be effectively changed in-situ to control stress without affecting other part qualities such as porosity, homogeneity, or strength. Vasinonta et al. mapped residual stress in thin wall formation, and proposed that build plate and part preheating is much more effective in reducing residual stresses than varying scan speed or laser power [26], [27]. Though Vasinonta et al. did not include re-heating of lower layers or adjacent scan tracks, this may indicate that control schemes that target minimization of residual stress may focus on monitoring build plate and chamber temperature, rather than monitoring melt-pool signatures. As mentioned, scan pattern has been shown to relate to residual stress formation, though this may be more difficult to adaptively control than build plate or chamber temperature.

The re-heating phenomenon also has an effect on metallic phase structure, (not to be confused with the more often modeled powder-liquid-solid phases). Wang and Fenicelli et al. [123], [127] looked at metal phase change based on temperature cycle history and volume fraction of three possible phases (in 410 stainless steel) using commercial welding simulation software. In the simulation results in [123], they observed that the high temperatures caused by the initial pass by the DED system laser would create a high-strength, martensitic microstructure. Key to these phase changes was the high rate of cooling observed in their model, a consequence of the material thermal properties, boundary conditions, and overall geometry. In [152], they extended the model to predict thermally and mechanically induced residual strain vs. laser power, scan speed, and powder flow rate (in a DED system), then compared to neutron-diffraction strain measurement results from [153] with good agreement for the range of parameters studied. Though results were complex and cannot all be detailed here, one interesting result showed that residual stress in the laser scan direction changed from compressive to tensile when scan speed doubled from $4.2 \mathrm{~mm} / \mathrm{s}$ to $8.5 \mathrm{~mm} / \mathrm{s}$, while maintaining the steady melt-pool size by adjusting laser power (increasing with scan speed, but decreasing with pass number).

Modeling and simulation can link measurable melt-pool or process signatures to immeasurable but critical phenomena like instantaneous material phase and microstructure. However these complex relationships require an organized and simplified methodology to implement in in-situ control. Perhaps the best method is through development of process maps, which several research groups have developed using modeling and simulations for the DED process for process control. Vasinonta et al. used a finite element (FE) method to develop process maps for the DED manufacturing of thin walls, and put results in term of nondimensional parameters based on the Rosenthal moving point source solution [26], [126], [129]. Bontha et al., used a 2D analytical (Rosenthal) and finite element models to calculate cooling rates in DED processing of Ti-6Al-4V as a function of laser power, traverse speed, and increasing build depth [154]. These are overlaid onto previously developed process maps that detail expected microstructure forms for different ranges of thermal gradients versus solidification rates ("G-R plot" or "solidification map" [155]). Soylemez et al., formed process maps that linked melt-pool signatures to laser power versus scan velocity (called a "P-V map") using a 3D FE simulation of single bead deposition [141], then later Gockel and Beuth combined the maps to show how specific combinations of laser power and speed can achieve constant grain size and tailored morphology in an electron beam wire feed process shown in Figure 4 [156]. They proposed use of this hybrid microstructure map, which depends on simulation data to develop, for "real-time indirect microstructure control through melt-pool dimension control." Though 
microstructure control is the primary focus in [156], it may be possible to extend this methodology to develop process maps for residual stress [26], [27]. Much of this reviewed process mapping work was centered at Carnegie Mellon and Wright State universities, and a thorough review of these efforts is given by Beuth et al., including a list of patent applications submitted by the authors [157].

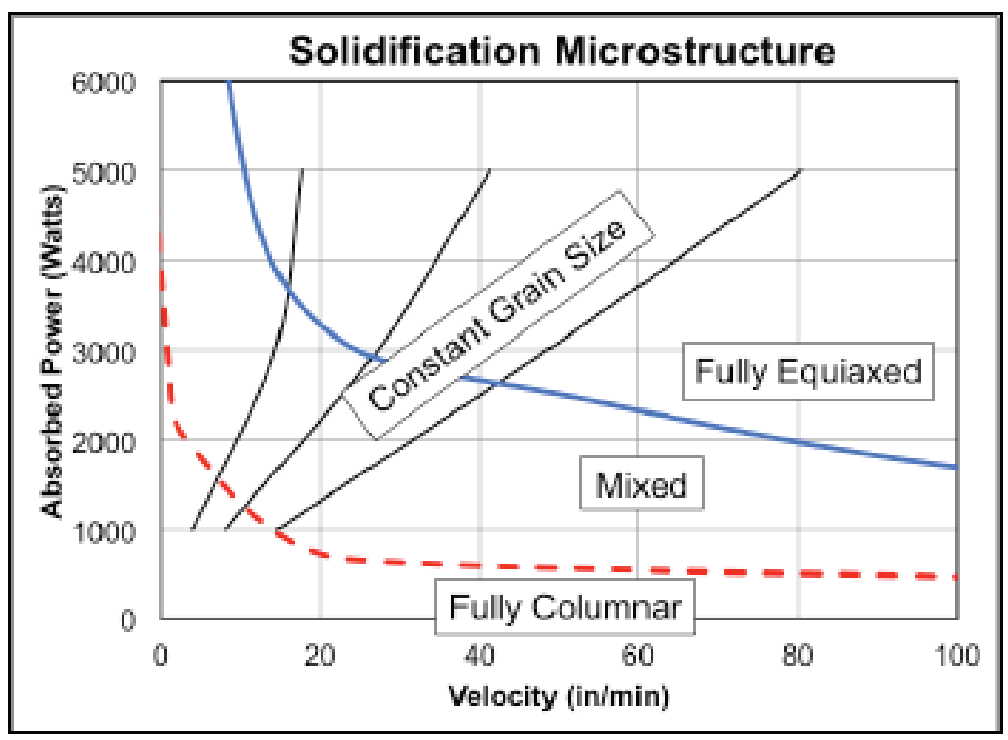

Figure 4. Microstructure P-V map for wire-fed E-beam Ti-6Al-4V (from Gockel and Beuth [156])

\section{Implications for Process Control}

Based on the review presented in Section 3, this section first identifies and categorizes the process parameters, process signatures, and product qualities as reported in the literature to systematically analyze the needed correlations among them. Next, the section presents the research opportunities specifically for the real-time control of AM PBF processes.

\subsection{Parameters-Signatures-Qualities Categorization}

As summarized in the previous sections, the influence of AM process parameters on the resultant part quality in general has been widely studied and reported. To establish foundations for process control, we sub-categorize the process parameters, process signatures and product quality according to the abilities to be measured and/or controlled. Process parameters are input to the PBF process and they are either potentially controllable or predefined. Controllable parameters (e.g., laser and scanning parameters, layer thickness, and temperature) are used to control the heating, melting, and solidification process and thus control the part quality. Predefined parameters, for example, include part geometry, material, and build plate parameters. Controllable process parameters generally correlate to the observable and derived process signatures (e.g., melt-pool size, temperature, porosity, or residual stress). Derivable parameters cannot be directly measured but can be calculated with a numerical model, such as the maximum depth of a melt-pool. For purposes of correlations we further subdivide the process signatures into three categories namely: melt-pool, track, and layer. Process signatures determine the final product qualities (geometric, mechanical, and physical). Developing correlations between the controllable process parameters and process signatures should support feed forward and feedback control, with the goal of embedding process 
knowledge into future control schemes. Figure 5 categorizes and lists the process parameters, process signatures, and product qualities to derive needed correlations.

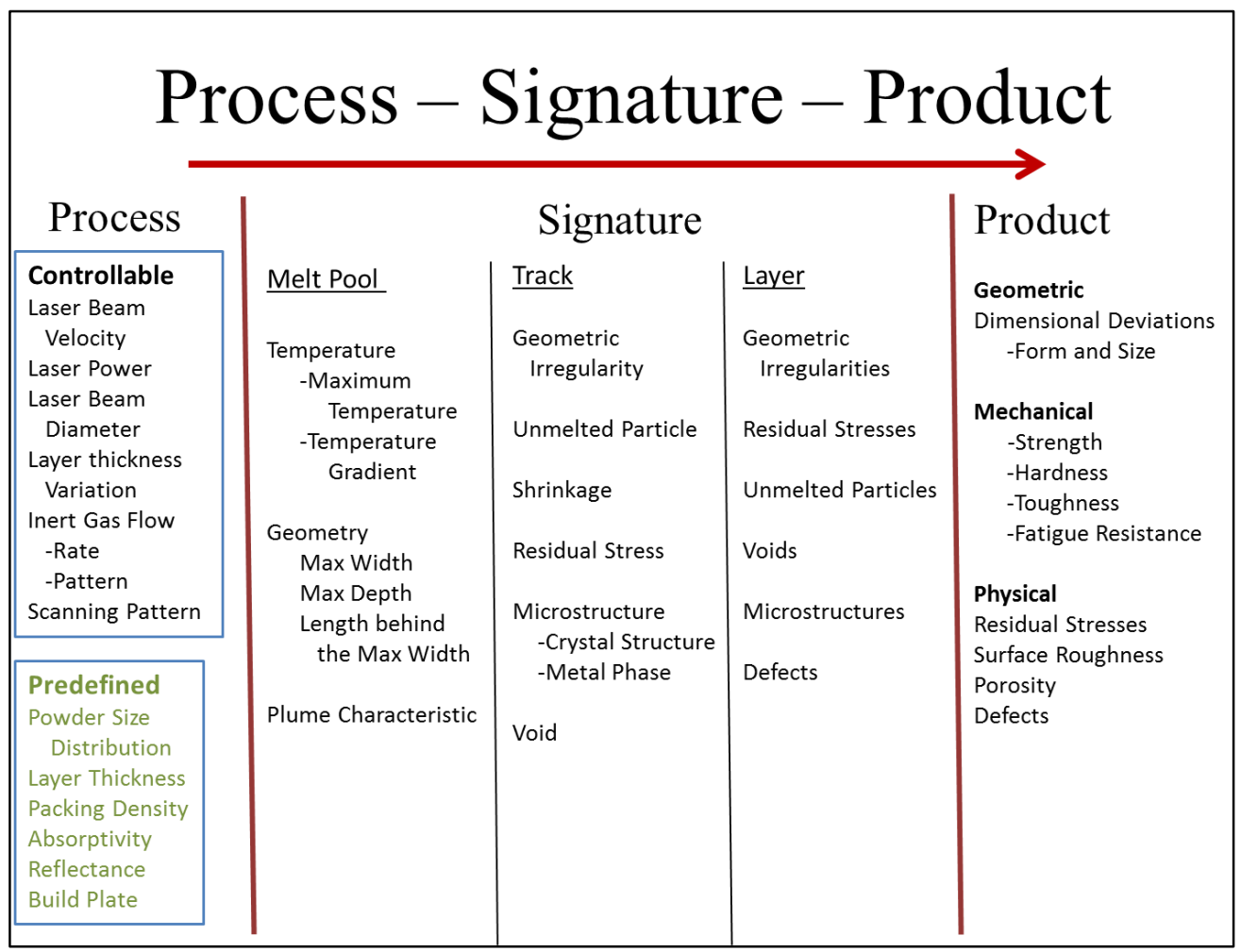

Figure 5. Parameters in the correlations

The main process controllable parameters include the following:

(1) Laser Beam Velocity: quantifies the scanning speed and direction of the laser beam.

(2) Laser Power: quantifies the power of the laser beam.

(3) Laser Beam Diameter: quantifies the diameter of the laser beam scanning the powder bed.

(4) Layer Thickness Variation: quantifies the variation to the preset powder layer thickness for refilling the previously fabricated sub-layer.

(5) Inert Gas Flow: quantifies the inert gas flowing above the powder bed for cooling using two subparameters namely the Flow Rate and the Flow Pattern, such as laminar flow, turbulent flow, or transient flow, of the inert gas.

(6) Scanning Pattern: quantifies the order of the scanning directions of the laser beam.

Predefined process parameters are those process-related parameters that are defined prior to laser scanning and cannot be changed during scanning. The following are the predefined parameters:

(1) Powder Size Distribution: quantifies the particle size distribution of the metal powder.

(2) Layer Thickness: quantifies the predetermined thickness of powder layer for each layer of scanning.

(3) Packing Density: quantifies the density of powder in the powder chamber after packing.

(4) Absorptivity: quantifies the coefficient of the heat absorbed per unit mass of powder. 
(5) Reflectance: quantifies the ratio of the heat reflected by the powder bed to the heat delivered by the laser beam.

(6) Build Plate: indicates the type of plate that is used to fabricate a product.

Melt-pool, a subcategory of process signature, has the following parameters:

(1) Temperature: includes two sub-parameters namely the Maximum Temperature of the melt-pool, and the Temperature Gradient of the melt-pool.

(2) Geometry: includes three sub-parameters namely Maximum Width of the melt-pool, Maximum Depth of the melt-pool, and Length of the melt-pool behind the maximum width.

(3) Plume Characteristic: characterizes the plume.

Track, another subcategory of process signature, has the following parameters:

(1) Geometric Irregularity: indicates irregularities in the track (e.g., balling, voids, discontinuity, and delamination) causing the fabricated track to deviate from the desired track.

(2) Unmelted Particle: indicates the location of an unmelted particle in the track.

(3) Shrinkage: indicates the size reduction due to cooling and solidification of the track.

(4) Residual Stress: quantifies residual stress in the track due to shrinkage or deformation, such as bending and twisting.

(5) Microstructure: indicates microstructure of the track denoted using two sub-parameters namely Crystal Structure (including grain size and grain growth direction) and Metal Phase.

(6) Void: indicates the location and shape of an empty space, such as pore, crack, and delamination, in the track.

Layer, the other subcategory of process signature, has the following parameters:

(1) Geometric Irregularities: indicates irregularities in the layer. Combined shape irregularities from all the tracks in a layer can make the entire fabricated layer to deviate in shape.

(2) Residual Stresses: indicates the residual stresses and stress distribution in the layer.

(3) Unmelted Particles: indicates particles, which are not melted by the laser beam, in the layer.

(4) Voids: quantifies empty spaces, such as pores, cracks, and delamination, in the layer.

(5) Microstructure: indicates the crystal structures and metal phase in the layer.

(6) Defects: quantifies imperfections (e.g., delamination, discontinuity, and severe deformation) in the layer such that the product can be disqualified if the defect cannot be remedied in fabricating the succeeding layers.

The category of Product includes the following:

(1) Dimensional deviation: quantifies the deviation of the measured dimension from the nominal dimension due to form and size errors.

(2) Mechanical property: quantifies mechanical performance of the product, such as strength, hardness, toughness, and fatigue resistance.

(3) Surface Roughness: quantifies the roughness of a surface of the product.

(4) Porosity: quantifies the amount of voids in the product.

(5) Defects: quantifies imperfections in the product that makes the product fail to perform by design.

(6) Residual Stress: quantifies unintended residual stress in the product. 


\subsection{Correlations}

With the parameters individually defined in the previous section, this section describes qualitative correlations to describe the cause-and-effect relationship between process control parameters, process signatures, and product quality. The correlations are synthesized according to literature review in the previous sections, particularly, Section 3. Most reviewed papers discussed the correlations between process parameters and product quality (e.g., increasing laser power can improve product mechanical strength due to deeper and wider melting). Those papers that discussed process signatures mostly focused on melt-pool temperature and area. Process parameters along with signatures in general have not yet been directly related to product quality.

From the literature, process parameters are driving factors that determine a melt-pool formation. Figure 6 shows the correlations between controllable process parameters and melt-pool signature parameters. Meltpool Temperature and Melt-pool Geometry depend on the controllable (Beam Diameter, Beam Power, and Beam Velocity) and predefined parameters (Reflectance, Absorptivity, Packing Density, Layer Thickness, Powder Size Distribution, Previous Layer/Substrate, and Build Plate). Plume Characteristic generally depends on the Beam Diameter, Beam Power, Beam Velocity, Scanning Strategy, and Inert Gas Flow (including flow rate flow pattern).

Note that in the paragraph text, the causes of cause-and-effect relationships are capitalized and the effects are capitalized and italicized for reading convenience. The effects are bolded in the figures that follow.
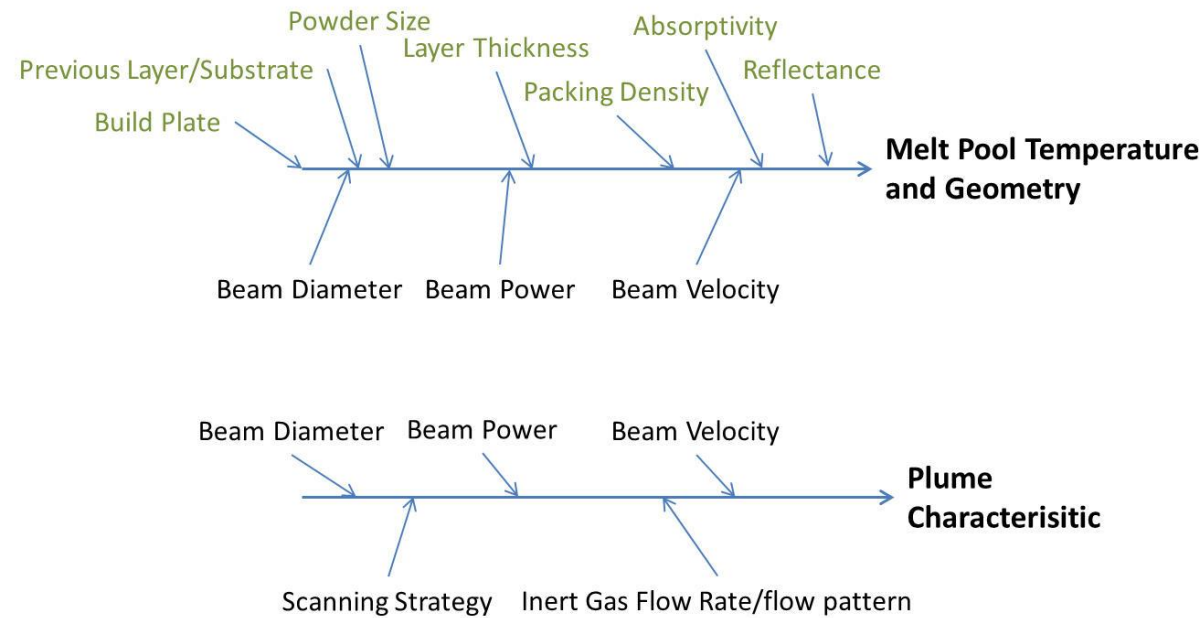

Figure 6. Correlations between Process and Melt-pool Signature

After the melt-pool cools, the metal solidifies and forms a track. From Figure 7, Shrinkage depends on the controllable process parameters namely the Layer Thickness Variation and Powder Packing Density. The thicker the layer, the more the metal shrinks. The higher the powder packing density, the less the metal shrinks. The Geometric Irregularity depends on Melt-pool Temperature, Melt-pool Geometry, Shrinkage, Beam Velocity, and Layer Thickness. If the Melt-pool Temperature is too high, the shape of the track will be wider due to extreme melting. If the Melt-pool Geometry is larger than the desired geometry, the track shape will become too large. Shrinkage deforms the shape of the track from the shape of the powder layer. If the Beam Velocity is too fast, balling occurs and causes Geometric Irregularity in the track. 

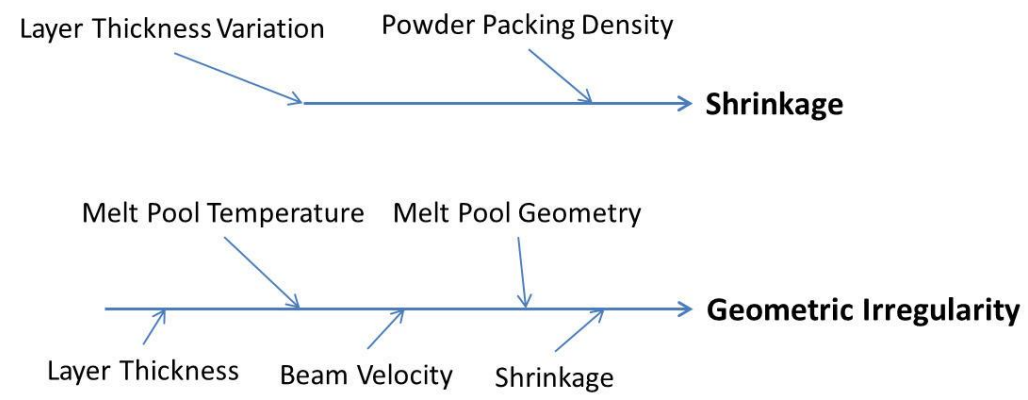

Figure 7. Correlations between Melt-pool and Track (1/3)

From Figure 8, Residual Stress is the maximum residual stress in the track and depends on Shrinkage, Temperature Gradient, Fabricating Adjacent Track, Beam Velocity, and Scanning Strategy. The more the melt-pool shrinks during solidification, the higher the residual stress is. Similarly, the steeper the Temperature Gradient, the higher is the Residual Stress. Unmelted Particles depends on Melt-pool Geometry, Melt-pool Temperature, Layer Thickness, and Fabricating Adjacent Track (Figure 8). If the Melt-pool Temperature is lower than the ideal temperature, Unmelted particles can occur because of incomplete melting. If the Melt-pool Geometry is irregular, some particles cannot have sufficient heat to melt and become Unmelted particles. The thicker the layer, more particles in the bottom of the melt-pool tend to exist. Fabricating an adjacent track can remelt the Unmelted particles.
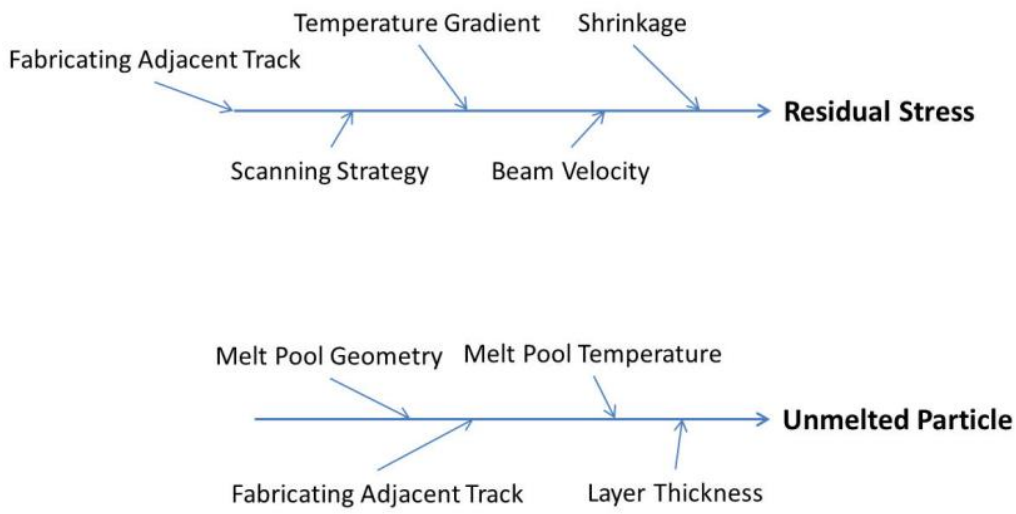

Figure 8. Correlations between Melt-pool and Track (2/3)

From Figure 9, Voids depend on Melt-pool Geometry, Melt-pool Temperature, and Fabricating Adjacent Track. Similar to Unmelted particles, if the Melt-pool Geometry is irregular, some particles will not have the sufficient heat to melt, and pores will be in the track. Similarly, if the Melt-pool Temperature is lower than the ideal temperature, Unmelted particles can occur because of incomplete melting, and pores will be in the track. Fabricating an adjacent track can remelt the Unmelted particles and, thus, remove Voids. Microstructure includes grain size, grain growing direction, and metal phase and depends on the following melt-pool parameters: Melt-pool Temperature, Temperature Gradient, Beam Velocity, and Fabricating Adjacent Track. The three parameters i.e., Melt-pool Temperature, Temperature Gradient, and Beam Velocity affect grain sizes, grain growing directions, and metal phases of the track. Fabricating 
Adjacent Track remelts a portion of the previous track as a heat treatment and thus affects the Microstructure of the track.

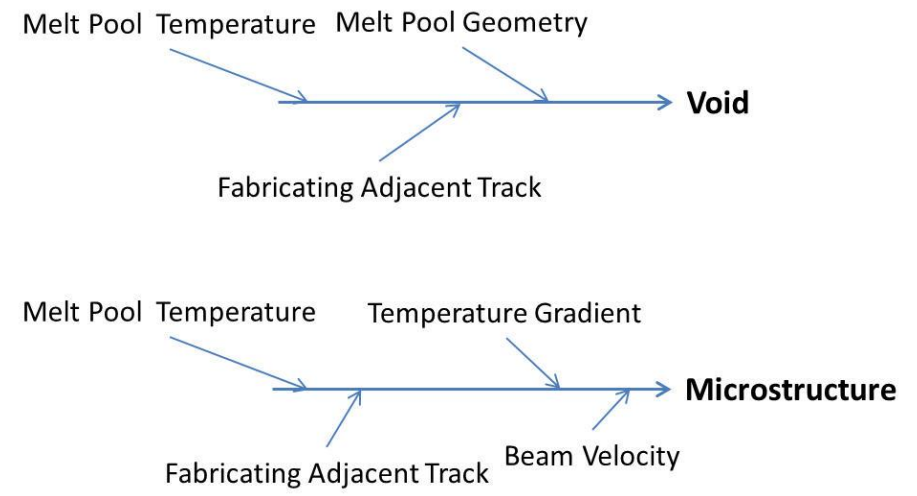

Figure 9. Correlations between Melt-pool and Track (3/3)

After tracks are fabricated, a layer of metal is formed. Figure 10 shows the layer related signatures namely: Geometric Irregularities, Residual Stresses, and Unmelted Particles. Geometric Irregularities of the layer depends on the combined track geometric irregularities. Residual Stresses of the layer depends on the Combined Track Residual Stresses and Fabricating Other Layers. Fabricating Other Layers can release or worsen the Residual Stress in the layer. The Unmelted Particles parameter is derived from the Combined Track Unmelted Particles.
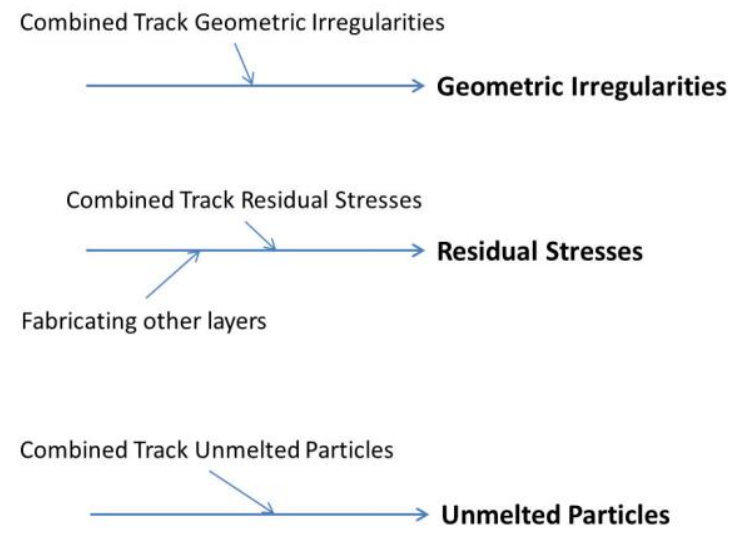

Figure 10. Correlations between Track and Layer (1/2)

Figure 11 shows the other layer related signatures namely Voids, Microstructures, and Defects. Voids are derived from both the Voids In Tracks and Between Tracks parameter and the Geometric Irregularity parameter. Microstructures depends on the Combined Track Microstructures parameter. Defects depend on the Shape Irregularities, Combined Track Microstructures, Residual Stresses, and Unmelted Particles. Defects indicates the locations, and the types of defects in a layer. If the defects can be remedied in the succeeding layer fabrication, the defects will not be the reason to stop the fabrication process; otherwise, the fabrication process should be stopped to avoid making a product with defects. 

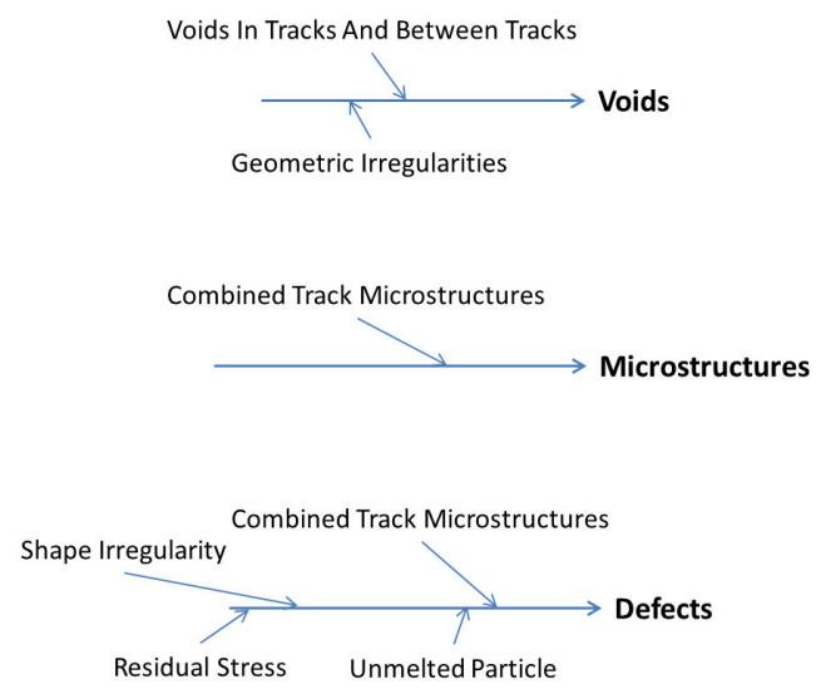

Figure 11. Correlations between Track and Layer (2/2)

Product quality directly depends on Dimensional Deviations, Surface Roughness, Mechanical Properties, Residual Stresses, Porosity, and Defects. Dimensional Deviations includes form and size deviations from the desired form and dimensions. From Figure 12, Dimensional Deviations depend on Combined Layer Dimensions and Combined Layer Geometric Irregularities. Surface Roughness depends on Voids (voids on the product surface) and Geometric Irregularities (geometric irregularities on the product surface). Mechanical Properties (including part mechanical strength, hardness, toughness, and fatigue performance) depends on the Combined Layer Microstructures, the Geometric Irregularities, Voids, Unmelted Particle, and Combined Layer Residual Stress.
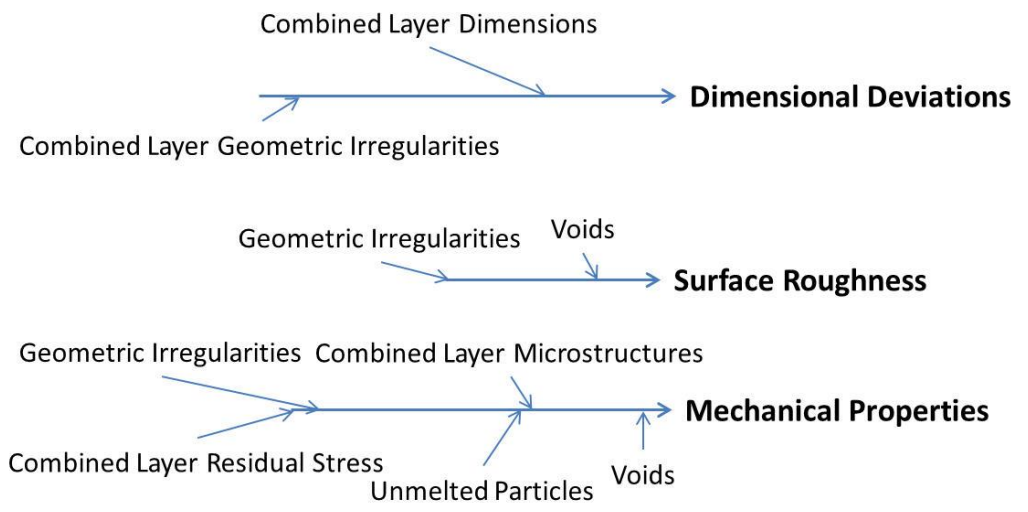

Figure 12. Correlations between Layer and Product (1/2)

From Figure 13, Residual Stresses in the product depends on Geometric Irregularities, Combined Microstructures, Voids, Unmelted Particles, and Combined Layer Residual Stress. The Combined Layer Residual Stress is main contributor to the Residual Stress in the product. Porosity depends on Voids in all the layers. Lastly, Defects (includes delamination, substandard mechanical properties, and out of 
tolerances) depends on Combined Voids In Layers, Unmelted Particles, Geometric Irregularities, and Residual Stresses.

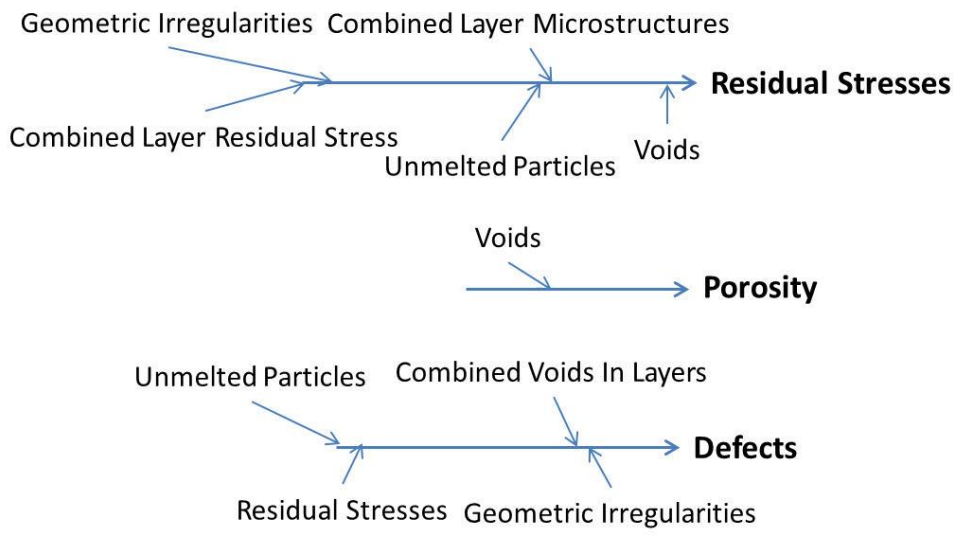

Figure 13. Correlations between Layer and Product (2/2)

From the above discussions, various correlations have been qualitatively connected through cause-andeffect diagrams from process parameters to process signatures and to part qualities. Change in one process parameter can affect multiple signatures and multiple part qualities. Part quality generally depends on multiple process parameters. Process and product usually follow a multiple input and multiple output relationship.

There are potentially other missing parameters. One possible missing process signature is the heat absorption, before the actual Melt-pool formation. The heat absorption signature can include the heat absorption rate and the temperature raising profile. More research in this subject is needed.

\subsection{Research Opportunities}

For design of AM PBF process control there must be further development of parameter-signature-quality relationships and relative sensitivities of those relationships through experiments and simulations. Existing control design for the DMD process focuses on measuring and controlling melt-pool signatures (size and temperature) by varying laser parameters (power and scan speed), and there is reason to believe PBF process control will follow similar trends. Therefore, for controller development, research results ought to focus on the parameter-signature-quality relationships and sensitivities, with particular focus on measureable melt-pool signatures, and controllable process parameters.

In addition to further defining these process relationships, new traceable measurement methods and identification of new measurable process signatures are necessary. Two issues, residual stress and varying metallic phase structure, are particularly problematic in PBF processes yet there are few or no in-situ, nonintrusive measurement methods available to detect these phenomena as they vary during a build. Melt-pool signatures (e.g., size and temperature) are the most often considered measurands for in-situ feed-back control. However, there is potential for other, less considered signatures that may offer greater sensitivity to process variations or simplified measurement, for example, measurements of the laser ablation plume size, or the spectral measurements of the ablation zone [158]-[160]. Methods for 
controlling porosity, surface finish, and residual stress will be necessary for increasing the endurance limit.

Most of the reviewed literature has limited analysis of measurement error and traceability, and there is a need for better measurement uncertainty evaluations and reporting. First, simulations require accurate and repeatable measurements for validation. For example, there are simulations that correlate temperature to melt-pool size. In such cases, a large uncertainty in a temperature evaluation will result in an uncertainty of the melt-pool size, and therefore inadequate comparison of measurement data with the model output. Better understanding of measurement uncertainty assists system controller design by identifying the necessary level of precision required to attain the goals of the control system.

It is well known that the relationships between parameters in the PBF process are complex. Process maps, such as those in [24], [26], [27], [129], [154], [157], will be a key tool to organize and communicate the complex, multi-dimensional parameter relationship topology. These maps will be essential for multiinput, multi-output (MIMO) control algorithm design, and model-based predictive controller design.

The AM process control design landscape is so far limited in variety, with most examples using melt-pool temperature and/or size to control laser power or speed. This method could very well be the most effective, however there is wider potential for different levels of control loops. For example, control loops may occur discretely between completion of each build layer rather than continuously (e.g., the powder bed temperature mapping by Craeghs et al. [8]). However, it is yet unclear which signatures are best modeled or measured, and which input parameters are best controlled for which time scale (either continuously or discrete inter-layer). It is a worthwhile endeavor to create an AM control loop architecture that identifies the multiple potential control loops, and provides a basis for identifying which loops are optimal for controlling which parameter-signature-quality relationship.

\section{Conclusions}

This report presented a review on the AM process control schemes, process measurements, and modeling and simulation methods as applied to the powder bed fusion process, though related work from other processes were also reviewed. This background study aimed to identify and summarize the measurement science needs that are critical to real-time AM process control. The report was organized to present the correlations between process parameters, process signatures, and product quality. Based on the review, we presented the implications for process control highlighting the research opportunities and future directions. For example, we found reported correlations between the laser power (process parameter) and the melt-pool surface geometry and surface temperature (process signatures) on the resulting relative density of the part (part quality). Melt-pool size and temperature have already been used as feedback parameters in closed-loop control schemes. Considering residual stresses as another example, researchers have identified that an increase in the build platform temperature correlates to lower residual stresses. There were also reported correlations on the residual stress to the scan strategy and layer thickness used to build. In the future work, newer process signatures and corresponding correlations will have to be investigated for newer control schemes.

Future work at NIST will also involve the development of a benchtop open architecture AM research platform to test and demonstrate the in-process measurement and control methods. Such a benchtop 
platform will enable us to directly observe melting and solidification of metal powders, integrate process metrology tools, and implement software interfaces and data acquisition for process measurements, as well as test the control algorithms. The AM community can benefit from such a test platform to implement, test, and validate a real-time and closed-loop control of AM processes.

\section{Disclaimer}

Certain products or services are identified in the paper to foster understanding. Such identification does not imply recommendation or endorsement by the National Institute of Standards and Technology, nor does it imply that the products or services identified are necessarily the best available for the purpose.

\section{References}

[1] ASTM Standard 2792, "Standard terminology for additive manufacturing technologies," ASTM International, West Conchocken, PA, 2012.

[2] Department of Commerce, "Fact Sheet: Additive Manufacturing," 15-Aug-2012. [Online]. Available: $\quad$ http://www.commerce.gov/news/fact-sheets/2012/08/15/fact-sheet-additivemanufacturing. [Accessed: 15-Dec-2014].

[3] T. Wohlers, "U.S. Manufacturing Competitiveness Initiative Dialogue," presented at the Council on Competitiveness, Oak Ridge, TN, 18-Apr-2013.

[4] Energetics Inc. for National Institute of Standards and Technology, "Measurement science roadmap for metal-based additive manufacturing," May-2013. [Online]. Available: http://www.nist.gov/el/isd/upload/NISTAdd_Mfg_Report_FINAL-2.pdf. [Accessed: 15-Dec-2014].

[5] D. L. Bourell, M. C. Leu, and D. W. Rosen, "Roadmap for additive manufacturing: identifying the future of freeform processing," Univ. Tex. Austin, 2009.

[6] T. Craeghs, F. Bechmann, S. Berumen, and J.-P. Kruth, "Feedback control of Layerwise Laser Melting using optical sensors," Phys. Procedia, vol. 5, pp. 505-514, 2010.

[7] T. Craeghs, S. Clijsters, E. Yasa, and J.-P. Kruth, "Online quality control of selective laser melting," in Solid Freeform Fabrication Proceedings, Austin, TX, 2011, pp. 212-226.

[8] T. Craeghs, S. Clijsters, J.-P. Kruth, F. Bechmann, and M.-C. Ebert, "Detection of Process Failures in Layerwise Laser Melting with Optical Process Monitoring," Laser Assist. Net Shape Eng. 7 LANE 2012, vol. 39, no. 0, pp. 753-759, 2012.

[9] K. A. Mumtaz and N. Hopkinson, "Selective Laser Melting of thin wall parts using pulse shaping," J. Mater. Process. Technol., vol. 210, no. 2, pp. 279-287, Jan. 2010.

[10] Y. Ning, Y. Wong, J. Y. Fuh, and H. T. Loh, "An approach to minimize build errors in direct metal laser sintering," Autom. Sci. Eng. IEEE Trans. On, vol. 3, pp. 73-80, 2006.

[11] A. Simchi, F. Petzoldt, and H. Pohl, "On the development of direct metal laser sintering for rapid tooling," J. Mater. Process. Technol., vol. 141, pp. 319-328, 2003.

[12] X. Wang, "Calibration of shrinkage and beam offset in SLS process," Rapid Prototyp. J., vol. 5, no. 3, pp. 129-133, 1999.

[13] M. Mahesh, Y. Wong, J. Fuh, and H. Loh, "A Six-sigma approach for benchmarking of RP\&M processes," Int. J. Adv. Manuf. Technol., vol. 31, no. 3-4, pp. 374-387, 2006.

[14] C. Doumanidis and Y.-M. Kwak, "Geometry modeling and control by infrared and laser sensing in thermal manufacturing with material deposition," J. Manuf. Sci. Eng., vol. 123, no. 1, pp. 45-52, 2001. 
[15] P. Aggarangsi, J. L. Beuth, and M. L. Griffith, "Melt pool size and stress control for laser-based deposition near a free edge," in Solid Freeform Fabrication Proceedings, Austin, TX, 2003, pp. 196-207.

[16] P. Aggarangsi, J. L. Beuth, and D. D. Gill, "Transient changes in melt pool size in laser additive manufacturing processes," in Solid Freeform Fabrication Proceedings, Austin, TX, 2004, pp. 1631747.

[17] A. Birnbaum, P. Aggarangsi, and J. L. Beuth, "Process scaling and transient melt pool size control in laser-based additive manufacturing processes," in Solid Freeform Fabrication Proceedings, Austin, TX, 2003, pp. 328-339.

[18] A. Birnbaum, J. L. Beuth, and J. W. Sears, "Scaling effects in laser-based additive manufacturing processes," in Solid Freeform Fabrication Proceedings, Austin, TX, 2004, pp. 151-162.

[19] M. R. Boddu, R. G. Landers, and F. W. Liou, "Control of laser cladding for rapid prototypingAreview," in Solid Freeform Fabrication Proceedings, Austin, TX, 2001, pp. 6-8.

[20] D. L. Cohen, "Additive Manufacturing of Functional Constructs Under Process Uncertainty," Ph.D. Dissertation, Cornell University, Ithaca, NY, 2010.

[21] G. Bi, A. Gasser, K. Wissenbach, A. Drenker, and R. Poprawe, "Characterization of the process control for the direct laser metallic powder deposition," Surf. Coat. Technol., vol. 201, no. 6, pp. 2676-2683, Apr. 2006.

[22] D. Hu and R. Kovacevic, "Sensing, modeling and control for laser-based additive manufacturing," Int. J. Mach. Tools Manuf., vol. 43, no. 1, pp. 51-60, Jan. 2003.

[23] D. Hu, H. Mei, and R. Kovacevic, "Improving Solid Freeform Fabrication Bylaser-Based Additive Manufacturing," Proc. Inst. Mech. Eng. Part B J. Eng. Manuf., vol. 216, pp. 1253-1264, 2002.

[24] S. Bontha and N. Klingbeil, "Thermal process maps for controlling microstructure in laser-based solid freeform fabrication," presented at the Solid Freeform Fabrication Proceedings, 2003, pp. 219-226.

[25] M. L. Griffith, W. H. Hofmeister, G. A. Knorovsky, D. O. MacCallum, M. E. Schlienger, and J. E. Smugeresky, "Direct laser additive fabrication system with image feedback control," 6,459,951, 01-Oct-2002.

[26] A. Vasinonta, J. L. Beuth, and M. L. Griffith, "Process maps for controlling residual stress and melt pool size in laser-based SFF processes," in Solid Freeform Fabrication Proceedings, Austin, TX, 2000, pp. 200-208.

[27] A. Vasinonta, M. L. Griffith, and J. L. Beuth, "Process maps for predicting residual stress and melt pool size in the laser-based fabrication of thin-walled structures," J. Manuf. Sci. Eng., vol. 129, no. 1, pp. 101-109, Feb. 2007.

[28] P. Aggarangsi and J. L. Beuth, "Localized preheating approaches for reducing residual stress in additive manufacturing," in Solid Freeform Fabrication Proceedings, Austin, TX, 2006, pp. 709720.

[29] J.-P. Kruth, G. Levy, F. Klocke, and T. H. C. Childs, "Consolidation phenomena in laser and powderbed based layered manufacturing," CIRP Ann. - Manuf. Technol., vol. 56, no. 2, pp. 730-759, 2007.

[30] A. Cooke and J. A. Slotwinski, "Properties of metal powders for additive manufacturing: a review of the state of the art of metal powder property testing," US Department of Commerce, National Institute of Standards and Technology, NISTIR 7873, 2012.

[31] J. A. Slotwinski, E. J. Garboczi, P. E. Stutzman, C. F. Ferraris, S. S. Watson, and M. A. Peltz, "Characterization of metal powders used for additive manufacturing," J. Res. Natl. Inst. Stand. Technol., vol. 19, 2014.

[32] A. Amado, M. Schmid, G. Levy, and K. Wegener, "Advances in SLS powder characterization," in Solid Freeform Fabrication Proceedings, Austin, TX, 2011, vol. 7, p. 12. 
[33] I. Robertson and G. Schaffer, "Some effects of particle size on the sintering of titanium and a master sintering curve model," Metall. Mater. Trans. A, vol. 40, no. 8, pp. 1968-1979, 2009.

[34] H. Su and D. L. Johnson, "Master sintering curve: A practical approach to sintering," J. Am. Ceram. Soc., vol. 79, no. 12, pp. 3211-3217, Dec. 1996.

[35] R. K. McGeary, "Mechanical packing of spherical particles," J. Am. Ceram. Soc., vol. 44, no. 10, pp. 513-522, Oct. 1961.

[36] G. B. M. Cervera and G. Lombera, "Numerical prediction of temperature and density distributions in selective laser sintering processes," Rapid Prototyp. J., vol. 5, pp. 21-26, 1999.

[37] A. V. Gusarov, T. Laoui, L. Froyen, and V. Titov, "Contact thermal conductivity of a powder bed in selective laser sintering," Int. J. Heat Mass Transf., vol. 46, pp. 1103 - 1109, 2003.

[38] A. V. Gusarov and J.-P. Kruth, "Modelling of radiation transfer in metallic powders at laser treatment," Int. J. Heat Mass Transf., vol. 48, pp. 3423 - 3434, 2005.

[39] J. Karlsson, A. Snis, H. Engqvist, and J. Lausmaa, "Characterization and comparison of materials produced by Electron Beam Melting (EBM) of two different Ti-6Al-4V powder fractions," J. Mater. Process. Technol., vol. 213, no. 12, pp. 2109-2118, Dec. 2013.

[40] B. Liu, R. Wildman, C. Tuck, I. Ashcroft, and R. Hague, "Investigation the effect of particle size distribution on processing parameters optimisation in Selective Laser Melting process," in Solid Freeform Fabrication Proceedings, Austin, TX, 2011.

[41] A. B. Spierings and G. Levy, "Comparison of density of stainless steel 316L parts produced with selective laser melting using different powder grades," in Solid Freeform Fabrication Proceedings, Austin, TX, 2009, pp. 342-353.

[42] A. B. Spierings, N. Herres, and G. Levy, "Influence of the particle size distribution on surface quality and mechanical properties in AM steel parts," Rapid Prototyp. J., vol. 17, no. 3, pp. 195202, Apr. 2011.

[43] E. Tsotsas and H. Martin, "Thermal conductivity of packed beds: A review," Chem. Eng. Process. Process Intensif., vol. 22, no. 1, pp. 19-37, Jul. 1987.

[44] S. Berumen, F. Bechmann, S. Lindner, J.-P. Kruth, and T. Craeghs, "Quality control of laser- and powder bed-based Additive Manufacturing (AM) technologies," Phys. Procedia, vol. 5, Part B, pp. 617-622, 2010.

[45] Y. Chivel and I. Smurov, "On-line temperature monitoring in selective laser sintering/melting," Phys. Procedia, vol. 5, pp. 515-521, 2010.

[46] T. Craeghs, F. Bechmann, S. Berumen, and J.-P. Kruth, "Feedback control of Layerwise Laser Melting using optical sensors," Phys. Procedia, vol. 5, pp. 505-514, 2010.

[47] P. Lott, H. Schleifenbaum, W. Meiners, K. Wissenbach, C. Hinke, and J. Bültmann, "Design of an optical system for the in situ process monitoring of Selective Laser Melting (SLM)," Phys. Procedia, vol. 12, Part A, pp. 683-690, 2011.

[48] I. Yadroitsev, P. Krakhmalev, and I. Yadroitsava, "Selective laser melting of Ti6Al4V alloy for biomedical applications: Temperature monitoring and microstructural evolution," J. Alloys Compd., vol. 583, pp. 404-409, Jan. 2014.

[49] R. B. Dinwiddie, R. R. Dehoff, P. D. Lloyd, L. E. Lowe, and J. B. Ulrich, "Thermographic in-situ process monitoring of the electron-beam melting technology used in additive manufacturing," in Proceedings of the SPIE, 2013, vol. 8705, p. 87050K-87050K-9.

[50] S. Price, J. Lydon, K. Cooper, and K. Chou, "Experimental temperature analysis of powder-based electron beam additive manufacturing," in Proceedings of the 24th Solid Freeform Fabrication Symposium, Austin, 2013, pp. 162-173.

[51] S. Price, J. Lydon, K. Cooper, and K. Chou, "Temperature Measurements in Powder-Bed Electron Beam Additive Manufacturing," in Proceedings of the ASME 2014 International Mechanical Engineering Congress \& Exposition, Montreal, Canada, 2014. 
[52] E. Rodriguez, F. Medina, D. Espalin, C. Terrazas, D. Muse, C. Henry, and R. Wicker, "Integration of a Thermal Imaging Feedback Control System in Electron Beam Melting," WM Keck Cent. 3D Innov. Univ. Tex. El Paso, 2012.

[53] A. Wegner and G. Witt, "Process monitoring in laser sintering using thermal imaging," presented at the SFF Symposium, Austin, Texas, USA, 2011, pp. 8-10.

[54] W. Hofmeister and M. Griffith, "Solidification in direct metal deposition by LENS processing," JOM, vol. 53, no. 9, pp. 30-34, Sep. 2001.

[55] R. B. Dinwiddie, V. Kunc, J. M. Lindal, B. Post, R. J. Smith, L. Love, and C. E. Duty, "Infrared imaging of the polymer 3D-printing process," presented at the SPIE Sensing Technology+ Applications, 2014, pp. 910502-910502.

[56] H. Krauss, C. Eschey, and M. Zaeh, "Thermography for monitoring the selective laser melting process," in Proceedings of the 23rd Annual International Solid Freeform Fabrication Symposium, Austin, TX, 2012, pp. 999-1014.

[57] J.-P. Kruth, J. Duflou, P. Mercelis, J. Van Vaerenbergh, T. Craeghs, and J. De Keuster, "On-line monitoring and process control in selective laser melting and laser cutting," in Proceedings of the Laser Assisted Net Shape Engineering 5 (LANE), 2007, vol. 1, pp. 23-37.

[58] G. Bi, B. Schürmann, A. Gasser, K. Wissenbach, and R. Poprawe, "Development and qualification of a novel laser-cladding head with integrated sensors," Int. J. Mach. Tools Manuf., vol. 47, no. 3, pp. 555-561, 2007.

[59] S. P. Santospirito, K. Słyk, B. Luo, R. Łopatka, O. Gilmour, and J. Rudlin, "Detection of defects in laser powder deposition (LPD) components by pulsed laser transient thermography," 2013, vol. 8705, p. $87050 X-87050 X-11$.

[60] R. B. Dinwiddie, R. R. Dehoff, P. D. Lloyd, L. E. Lowe, and J. B. Ulrich, "Thermographic in-situ process monitoring of the electron-beam melting technology used in additive manufacturing," in Proceedings of the SPIE, 2013, vol. 8705, p. 87050K-87050K-9.

[61] R. B. Dinwiddie, L. J. Love, and J. C. Rowe, "Real-time process monitoring and temperature mapping of a 3D polymer printing process," in Proceedings of the SPIE, 2013, vol. 8705.

[62] S. Price, K. Cooper, and K. Chou, "Evaluations of temperature measurements by near-infrared thermography in powder-based electron-beam additive manufacturing," in Solid Freeform Fabrication Symposium, 2012, pp. 761-773.

[63] M. Pavlov, M. Doubenskaia, and I. Smurov, "Pyrometric analysis of thermal processes in SLM technology," Phys. Procedia, vol. 5, pp. 523-531, 2010.

[64] K. Masubuchi, Analysis of welded structures: Residual stresses, distortion, and their consequences. Pergamon Press, New York, 1980.

[65] B. Ekmekçi, N. Ekmekçi, A. Tekkaya, and A. Erden, "Residual stress measurement with layer removal method," Meas. Tech., vol. 1, p. 3, 2004.

[66] N. W. Klingbeil, J. L. Beuth, R. K. Chin, and C. H. Amon, "Residual stress-induced warping in direct metal solid freeform fabrication," Int. J. Mech. Sci., vol. 44, no. 1, pp. 57-77, 2002.

[67] Z. Gan, H. W. Ng, and A. Devasenapathi, "Deposition-induced residual stresses in plasma-sprayed coatings," Surf. Coat. Technol., vol. 187, no. 2, pp. 307-319, 2004.

[68] G. Branner, M. Zaeh, and C. Groth, "Coupled-Field Simulation in Additive Layer Manufacturing," presented at the Proceedings of the 3rd International Conference on Polymers and Moulds Innovations, 2008, pp. 184-193.

[69] I. A. Roberts, "Investigation of residual stresses in the laser melting of metal powders in additive layer manufacturing," 2012.

[70] M. Shiomi, "Residual stress within metallic model made by selective laser melting process," CIRP Ann., vol. 53, pp. $195-198,2004$. 
[71] L. Van Belle, G. Vansteenkiste, and J. C. Boyer, "Investigation of Residual Stresses Induced during the Selective Laser Melting Process," Key Eng. Mater., vol. 554-557, pp. 1828-1834, Jun. 2013.

[72] A. L. Cooke and S. P. Moylan, "Process Intermittent Measurement for Powder-Bed Based Additive Manufacturing," 22nd Int. SFF Symp. - Addit. Manuf. Conf., Aug. 2011.

[73] D. B. Pedersen, L. De Chiffre, and H. N. Hansen, "Additive Manufacturing: Multi Material Processing and Part Quality Control," 2013.

[74] S. Kleszczynski, J. zur Jacobsmühlen, J. Sehrt, and G. Witt, "Error detection in laser beam melting systems by high resolution imaging," presented at the Solid Freeform Fabrication Symposium, Austin, TX, 2012.

[75] E. Yasa, J. Deckers, T. Craeghs, M. Badrossamay, and J.-P. Kruth, "Investigation on occurrence of elevated edges in selective laser melting," presented at the International Solid Freeform Fabrication Symposium, Austin, TX, USA, 2009, pp. 673-85.

[76] K. Abd-Elghany and D. L. Bourell, "Property evaluation of $304 \mathrm{~L}$ stainless steel fabricated by selective laser melting," Rapid Prototyp. J., vol. 18, no. 5, pp. 420-428, Jul. 2012.

[77] R. Paul and S. Anand, "Process energy analysis and optimization in selective laser sintering," J. Manuf. Syst., vol. 31, no. 4, pp. 429-437, 2012.

[78] M. . Khaing, J. Y. . Fuh, and L. Lu, "Direct metal laser sintering for rapid tooling: processing and characterisation of EOS parts," 5th Asia Pac. Conf. Mater. Process., vol. 113, no. 1-3, pp. 269272, Jun. 2001.

[79] T. A. Krol, C. Seidel, and M. F. Zaeh, "Prioritization of Process Parameters for an Efficient Optimisation of Additive Manufacturing by Means of a Finite Element Method," Eighth CIRP Conf. Intell. Comput. Manuf. Eng., vol. 12, no. 0, pp. 169-174, 2013.

[80] J. Delgado, J. Ciurana, and C. A. Rodríguez, "Influence of process parameters on part quality and mechanical properties for DMLS and SLM with iron-based materials," Int. J. Adv. Manuf. Technol., vol. 60, no. 5-8, pp. 601-610, May 2012.

[81] D. Wang, Y. Yang, Z. Yi, and X. Su, "Research on the fabricating quality optimization of the overhanging surface in SLM process," Int. J. Adv. Manuf. Technol., vol. 65, no. 9-12, pp. 14711484, Apr. 2013.

[82] H. Meier and C. Haberland, "Experimental studies on selective laser melting of metallic parts," Mater. Werkst., vol. 39, no. 9, pp. 665-670, 2008.

[83] J. Sehrt and G. Witt, "Dynamic strength and fracture toughness analysis of beam melted parts," in Proceedings of the 36th International MATADOR Conference, Manchester, UK, 2010, pp. 385388.

[84] S. Storch, D. Nellessen, G. Schaefer, and R. Reiter, "Selective laser sintering: qualifying analysis of metal based powder systems for automotive applications," Rapid Prototyp. J., vol. 9, no. 4, pp. 240-251, Oct. 2003.

[85] I. Gibson and D. Shi, "Material properties and fabrication parameters in selective laser sintering process," Rapid Prototyp. J., vol. 3, pp. 129-136, 1997.

[86] A. Wegner and G. Witt, "Correlation of process parameters and part properties in laser sintering using response surface modeling," in Proceedings of the Laser Assisted Net Shape Engineering 7 (LANE), 2012, vol. 39, pp. 480-490.

[87] D. Manfredi, F. Calignano, M. Krishnan, R. Canali, E. P. Ambrosio, and E. Atzeni, "From powders to dense metal parts: Characterization of a commercial AlSiMg alloy processed through direct metal laser sintering," Materials, vol. 6, no. 3, pp. 856-869, 2013.

[88] I. Yadroitsev and I. Smurov, "Selective laser melting technology: From the single laser melted track stability to 3D parts of complex shape," Phys. Procedia, vol. 5, Part B, pp. 551-560, 2010. 
[89] I. Yadroitsev, L. Thivillon, P. Bertrand, and I. Smurov, "Strategy of manufacturing components with designed internal structure by selective laser melting of metallic powder," Appl. Surf. Sci., vol. 254, pp. 980-983, 2007.

[90] D. Buchbinder, W. Meiners, N. Pirch, K. Wissenbach, and J. Schrage, "Investigation on reducing distortion by preheating during manufacture of aluminum components using selective laser melting," J. Laser Appl., vol. 26, no. 1, p. 012004, 2013.

[91] C. Casavola, S. L. Campanelli, and C. Pappalettere, "Preliminary investigation on distribution of residual stress generated by the selective laser melting process," J. Strain Anal. Eng. Des., vol. 44, no. 1, pp. 93-104, Jan. 2009.

[92] J.-P. Kruth, J. Deckers, E. Yasa, and R. Wauthlé, "Assessing and comparing influencing factors of residual stresses in selective laser melting using a novel analysis method," Proc. Inst. Mech. Eng. Part B J. Eng. Manuf., vol. 226, no. 6, pp. 980-991, 2012.

[93] S. Leuders, M. Thöne, A. Riemer, T. Niendorf, T. Tröster, H. A. Richard, and H. J. Maier, "On the mechanical behaviour of titanium alloy TiAl6V4 manufactured by selective laser melting: Fatigue resistance and crack growth performance," Int. J. Fatigue, vol. 48, pp. 300-307, Mar. 2013.

[94] C. Casavola, S. Campanelli, and C. Pappalettere, "Experimental analysis of residual stresses in the selective laser melting process," presented at the 2008 SEM International Conference and Exposition on Experimental and Applied Mechanics, Orlando, FL, 2008.

[95] S. Dadbakhsh, L. Hao, and N. Sewell, "Effect of selective laser melting layout on the quality of stainless steel parts," Rapid Prototyp. J., vol. 18, no. 3, pp. 241-249, Apr. 2012.

[96] P. Mercelis and J.-P. Kruth, "Residual stresses in selective laser sintering and selective laser melting," Rapid Prototyp. J., vol. 12, no. 5, pp. 254-265, Oct. 2006.

[97] B. Vrancken, R. Wauthlé, J.-P. Kruth, and J. Van Humbeeck, "Study of the influence of material properties on residual stress in selective laser melting," 2013.

[98] M. F. Zaeh and G. Branner, "Investigations on residual stresses and deformations in selective laser melting," Prod. Eng., vol. 4, no. 1, pp. 35-45, Feb. 2010.

[99] T. Sercombe, N. Jones, R. Day, and A. Kop, "Heat treatment of Ti-6Al-7Nb components produced by selective laser melting," Rapid Prototyp. J., vol. 14, no. 5, pp. 300-304, 2008.

[100] P. J. Withers and H. K. D. H. Bhadeshia, "Residual stress. Part 2 - Nature and origins," Mater. Sci. Technol., vol. 17, no. 4, pp. 366-375, 2001.

[101] C. R. Knowles, T. H. Becker, and R. B. Tait, "Residual stress measurements and structural integrity implications for selective laser melted TI-6al-4v\#," South Afr. J. Ind. Eng., vol. 23, pp. 119-129, 2012.

[102] M. Thone, S. Leuders, A. Riemer, T. Tröster, and H. Richard, "Influence of heat-treatment on selective laser melting products-eg Ti6Al4V," presented at the Solid freeform fabrication symposium SFF, Austin Texas, 2012.

[103] R. Morgan, C. Sutcliffe, and W. O'neill, "Density analysis of direct metal laser re-melted 316L stainless steel cubic primitives," J. Mater. Sci., vol. 39, pp. 1195-1205, 2004.

[104] E. Yasa, J. Deckers, and J.-P. Kruth, "The investigation of the influence of laser re-melting on density, surface quality and microstructure of selective laser melting parts," Rapid Prototyp. J., vol. 17, no. 5, pp. 312-327, Aug. 2011.

[105] A. B. Spierings, K. Wegener, and G. Levy, "Designing material properties locally with additive manufacturing technology SLM," in Solid Freeform Fabrication Proceedings, Austin, TX, 2012, pp. 447-455.

[106] J. Parthasarathy, B. Starly, S. Raman, and A. Christensen, "Mechanical evaluation of porous titanium (Ti6Al4V) structures with electron beam melting (EBM)," J. Mech. Behav. Biomed. Mater., vol. 3, no. 3, pp. 249-259, 2010. 
[107] J.-P. Kruth, M. Badrossamay, E. Yasa, J. Deckers, L. Thijs, and J. Van Humbeeck, "Part and material properties in selective laser melting of metals," in Proceedings of the 16th International Symposium on Electromachining, Shanghai, China, 2010.

[108] H. Gu, H. Gong, D. Pal, K. Rafi, T. Starr, and B. Stucker, "Influences of energy density on porosity and microstructure of selective laser melted 17-4PH stainless steel," in Solid Freeform Fabrication Proceedings, Austin, TX, 2013, vol. 37.

[109] A. Chatterjee, S. Kumar, P. Saha, P. Mishra, and A. R. Choudhury, "An experimental design approach to selective laser sintering of low carbon steel," J. Mater. Process. Technol., vol. 136, pp. 151-157, 2003.

[110] K. A. Ghany and S. F. Moustafa, "Comparison between the products of four RPM systems for metals," Rapid Prototyp. J., vol. 12, no. 2, pp. 86-94, Mar. 2006.

[111] H. Stoffregen, J. Fischer, C. Siedelhofer, and E. Abele, "Selective laser melting of porous structures," in Solid Freeform Fabrication Proceedings, 2011, pp. 680-695.

[112] E. Brandl, U. Heckenberger, V. Holzinger, and D. Buchbinder, "Additive manufactured AlSi10Mg samples using Selective Laser Melting (SLM): Microstructure, high cycle fatigue, and fracture behavior," Mater. Des., vol. 34, no. 0, pp. 159-169, Feb. 2012.

[113] R. Khalid, N. V. Karthik, T. L. Starr, and B. E. Stucker, "Mechanical property evaluation of Ti-6Al-4V parts made using electron beam melting," in Solid Freeform Fabrication Proceedings, Austin, TX, 2012, pp. 526-535.

[114] P. Lipinski, A. Barbas, and A.-S. Bonnet, "Fatigue behavior of thin-walled grade 2 titanium samples processed by selective laser melting. Application to life prediction of porous titanium implants," $J$. Mech. Behav. Biomed. Mater., vol. 28, pp. 274-290, Dec. 2013.

[115] A. B. Spierings, T. L. Starr, and K. Wegener, "Fatigue performance of additive manufactured metallic parts," Rapid Prototyp. J., vol. 19, no. 2, pp. 88-94, Mar. 2013.

[116] E. Wycisk, C. Emmelmann, S. Siddique, and F. Walther, "High cycle fatigue (HCF) performance of Ti-6Al-4V alloy processed by selective laser melting," Adv. Mater. Res., vol. 816, pp. 134-139, 2013.

[117] H. K. Rafi, T. L. Starr, and B. E. Stucker, "A comparison of the tensile, fatigue, and fracture behavior of Ti-6Al-4V and 15-5 PH stainless steel parts made by selective laser melting," Int. J. Adv. Manuf. Technol., vol. 69, no. 5-8, pp. 1299-1309, 2013.

[118] K. Zeng, D. Pal, and B. E. Stucker, "A review of thermal analysis methods in laser sintering and selective laser melting," presented at the Solid Freeform Fabrication Symposium, Austin, TX, 2012.

[119] R. B. Patil and V. Yadava, "Finite element analysis of temperature distribution in single metallic powder layer during metal laser sintering," Int. J. Mach. Tools Manuf., vol. 47, pp. 1069-1080, 6.

[120] A. V. Gusarov, "Homogenization of radiation transfer in two-phase media with irregular phase boundaries," Phys. Rev. B, vol. 77, no. 14, p. 144201 1-14, Apr. 2008.

[121] S. Kolossov, E. Boillat, R. Glardon, P. Fischer, and M. Locher, "3D FE simulation for temperature evolution in the selective laser sintering process," Int. J. Mach. Tools Manuf., vol. 44, no. 2-3, pp. 117-123, Feb. 2004.

[122] I. A. Roberts, C. J. Wang, R. Esterlein, M. Stanford, and D. J. Mynors, "A three-dimensional finite element analysis of the temperature field during laser melting of metal powders in additive layer manufacturing," Int. J. Mach. Tools Manuf., vol. 49, no. 12-13, pp. 916-923, Oct. 2009.

[123] L., Felicelli, S., Gooroochurn, Y., Wang, P.T., Horstemeyer, M.F. Wang, "Optimization of the LENS ${ }^{\circledR}$ process for steady molten pool size," Mater. Sci. Eng. A, vol. 474, pp. 148-156, 2008.

[124] L. Wang and S. Felicelli, "Process modeling in laser deposition of multilayer SS410 steel," J. Manuf. Sci. Eng.-Trans. Asme, vol. 129, pp. 1028-1034, Dec. 2007. 
[125] J. D. Williams and C. R. Deckard, "Advances in modeling the effects of selected parameters on the SLS process," Rapid Prototyp. J., vol. 4, no. 2, pp. 90-100, Jun. 1998.

[126] D. Rosenthal, "The theory of moving sources of heat and its application to metal treatments," 1946.

[127] L. Wang and S. Felicelli, "Analysis of thermal phenomena in LENS (TM) deposition," Mater. Sci. Eng. -Struct. Mater. Prop. Microstruct. Process., vol. 435, pp. 625-631, Nov. 2006.

[128] A. V. Gusarov and I. Smurov, "Modeling the interaction of laser radiation with powder bed at selective laser melting," Phys. Procedia, vol. 5, pp. 381-394, 2010.

[129] A. Vasinonta, M. L. Griffith, and J. L. Beuth, "A process map for consistent build conditions in the solid freeform fabrication of thin-walled structures," J. Manuf. Sci. Eng., vol. 123, no. 4, pp. 615622, Aug. 2000.

[130] T. Chen and Y. Zhang, "Numerical simulation of two-dimensional melting and resolidification of a two-component metal powder layer in selective laser sintering process," Numer. Heat Transf. Part Appl., vol. 46, pp. 633-649, 2004.

[131] T. Chen and Y. Zhang, "Thermal modeling of laser sintering of two-component metal powder on top of sintered layers via multi-line scanning," Appl. Phys. A, vol. 86, no. 2, pp. 213-220, Feb. 2007.

[132] A. V. Gusarov, I. Yadroitsev, P. Bertrand, and I. Smurov, "Heat transfer modelling and stability analysis of selective laser melting," Appl. Surf. Sci., vol. 254, no. 4, pp. 975-979, Dec. 2007.

[133] M. Van Elsen, F. Al-Bender, and J.-P. Kruth, "Application of dimensional analysis to selective laser melting," Rapid Prototyp. J., vol. 14, pp. 15-22, 2008.

[134] C. Körner, E. Attar, and P. Heinl, "Mesoscopic simulation of selective beam melting processes," J. Mater. Process. Technol., vol. 211, no. 6, pp. 978-987, Jun. 2011.

[135] R. Ammer, M. Markl, U. Ljungblad, C. Körner, and U. Rüde, "Simulating fast electron beam melting with a parallel thermal free surface lattice Boltzmann method," in Proceedings of ICMMES-International Conference for Mesoscopic Methods for Engineering and Science, Taipei, Taiwan, 2012, vol. 67, pp. 318-330.

[136] E. Attar, "Simulation of Selective Electron Beam Melting Processes," Dr.-Ing., University of Erlangen, Nuremberg, Germany, 2011.

[137] W. Zhou, D. Loney, A. G. Federov, F. Degertekin, and D. Rosen, "Lattice Boltzmann simulations of multiple droplet interactions during impingement on the substrate," in Solid Freeform Fabrication Proceedings, Austin, TX, 2013, pp. 606-621.

[138] A. Hussein, L. Hao, C. Yan, and R. Everson, "Finite element simulation of the temperature and stress fields in single layers built without-support in selective laser melting," Mater. Des., vol. 52, pp. 638-647, Dec. 2013.

[139] L. Dong, A. Makradi, S. Ahzi, and Y. Remond, "Three-dimensional transient finite element analysis of the selective laser sintering process," J. Mater. Process. Technol., vol. 209, pp. 700-706, Jan. 2009.

[140] J. Yin, H. Zhu, L. Ke, W. Lei, C. Dai, and D. Zuo, "Simulation of temperature distribution in single metallic powder layer for laser micro-sintering," Comput. Mater. Sci., vol. 53, no. 1, pp. 333-339, Feb. 2012.

[141] E. Soylemez, J. L. Beuth, and K. Taminger, "Controlling melt pool dimensions over a wide range of material deposition rates in electron beam additive manufacturing," in Solid Freeform Fabrication Proceedings, Austin, TX, 2010, pp. 571-582.

[142] T. H. C. Childs, C. Hauser, and M. Badrossamay, "Selective laser sintering (melting) of stainless and tool steel powders: Experiments and modelling," J. Eng. Manuf., vol. 219, no. 4, pp. 339-357, Apr. 2005. 
[143] M. Shiomi, A. Yoshidome, F. Abe, and K. Osakada, "Finite element analysis of melting and solidifying processes in laser rapid prototyping of metallic powders," Int. J. Mach. Tools Manuf., vol. 39, no. 2, pp. 237-252, 1999.

[144] R. Li, Y. Shi, J. Liu, H. Yao, and W. Zhang, "Effects of processing parameters on the temperature field of selective laser melting metal powder," Powder Metall. Met. Ceram., vol. 48, no. 3-4, pp. 186-195, Mar. 2009.

[145] L. Wang, S. D. Felicelli, and J. Craig, "Thermal modeling and experimental validation in the LENS process," in Solid Freeform Fabrication Proceedings, Austin, TX, 2007, pp. 100-111.

[146] D. Gu and Y. Shen, "Effects of processing parameters on consolidation and microstructure of WCu components by DMLS," J. Alloys Compd., vol. 473, pp. 107-115, 2009.

[147] L. Van Belle, G. Vansteenkiste, and J. C. Boyer, "Comparisons of numerical modelling of the selective laser melting," Key Eng. Mater., vol. 504-506, pp. 1067-1072, Feb. 2012.

[148] M. Labudovic, D. Hu, and R. Kovacevic, "A three dimensional model for direct laser metal powder deposition and rapid prototyping," J. Mater. Sci., vol. 38, no. 1, pp. 35-49, 2003.

[149] M. Matsumoto, M. Shiomi, K. Osakada, and F. Abe, "Finite element analysis of single layer forming on metallic powder bed in rapid prototyping by selective laser processing," Int. J. Mach. Tools Manuf., vol. 42, pp. 61-67, 2002.

[150] K. Guan, Z. Wang, M. Gao, X. Li, and X. Zeng, "Effects of processing parameters on tensile properties of selective laser melted 304 stainless steel," Mater. Des., vol. 50, pp. 581-586, Sep. 2013.

[151] A. H. Nickel, D. M. Barnett, and F. B. Prinz, "Thermal stresses and deposition patterns in layered manufacturing," Mater. Sci. Eng. A, vol. 317, no. 1-2, pp. 59-64, Oct. 2001.

[152] L., Felicelli, S., Pratt, P. Wang, "Residual stresses in LENS-deposited AISI 410 stainless steel plates," Mater. Sci. Eng. A, vol. 496, pp. 234-241, 2008.

[153] P. Pratt, S. Felicelli, L. Wang, and C. Hubbard, "Residual stress measurement of laser-engineered net shaping AISI 410 thin plates using neutron diffraction," Metall. Mater. Trans. A, vol. 39, pp. 3155-3163, 2008.

[154] S. Bontha, N. W. Klingbeil, P. A. Kobryn, and H. L. Fraser, "Thermal process maps for predicting solidification microstructure in laser fabrication of thin-wall structures," J. Mater. Process. Technol., vol. 178, no. 1, pp. 135-142, 2006.

[155] P. A. Kobryn and S. L. Semiatin, "Microstructure and texture evolution during solidification processing of Ti-6Al-4V," J. Mater. Process. Technol., vol. 135, no. 2-3, pp. 330-339, Apr. 2003.

[156] J. Gockel and J. L. Beuth, "Understanding Ti-6Al-4V microstructure control in additive manufacturing via process maps," in Solid Freeform Fabrication Proceedings, Austin, TX, 2013, pp. 666-674.

[157] J. L. Beuth, J. Fox, J. Gockel, C. Montgomery, R. Yang, H. Qiao, E. Soylemez, P. Reeseewatt, A. Anvari, and S. Narra, "Process mapping for qualification across multiple direct metal additive manufacturing processes," in Solid Freeform Fabrication Proceedings, Austin, TX, 2013, pp. 655665.

[158] L. Song and J. Mazumder, "Real time Cr measurement using optical emission spectroscopy during direct metal deposition process," Sens. J. IEEE, vol. 12, no. 5, pp. 958-964, 2012.

[159] L. Song, V. Bagavath-Singh, B. Dutta, and J. Mazumder, "Control of melt pool temperature and deposition height during direct metal deposition process," Int. J. Adv. Manuf. Technol., vol. 58, no. 1-4, pp. 247-256, Jan. 2012.

[160] K. Bartkowiak, "Direct laser deposition process within spectrographic analysis in situ," in Proceedings of the Laser Assisted Net Shape Engineering 6 (LANE), 2010, vol. 5, Part B, pp. 623629. 
[161] F. Abe, K. Osakada, M. Shiomi, K. Uematsu, and M. Matsumoto, "The manufacturing of hard tools from metallic powders by selective laser melting," J. Mater. Process. Technol., vol. 111, no. 1-3, pp. 210-213, Apr. 2001.

[162] M. A. Saleh and A. E. Ragab, "Ti-6Al-4V Helical Spring Manufacturing via SLM: Effect of Geometry on Shear Modulus," in Proceedings of the International MultiConference of Engineers and Computer Scientists, Hong Kong, 2013, vol. 2.

[163] C. Casavola, S. Campanelli, and C. Pappalettere, "Experimental analysis of residual stresses in the selective laser melting process," 2008.

[164] D. Buchbinder, H. Schleifenbaum, S. Heidrich, W. Meiners, and J. Bültmann, "High power selective laser melting (HP SLM) of aluminum parts," Phys. Procedia, vol. 12, Part A, pp. 271-278, 2011.

[165] E. Louvis, P. Fox, and C. J. Sutcliffe, "Selective laser melting of aluminium components," J. Mater. Process. Technol., vol. 211, no. 2, pp. 275-284, Feb. 2011. 


\section{Appendix A}

\section{AM PBF Machine Specifications:}

Typically, metal PBF machines have build volumes on the order of $250 \mathrm{~mm}$ x $250 \mathrm{~mm}$ x $200 \mathrm{~mm}$. The metals that are available for production are stainless steels, tool steels, titanium alloys, nickel alloys, aluminum alloys, cobalt chrome alloys, and bronze alloys. Layer thicknesses are typically between 0.02 $\mathrm{mm}$ and $0.10 \mathrm{~mm}$. The process builds in an inert environment of nitrogen or argon (though some processes, especially electron-beam based processes, build in a vacuum). Laser-based systems typically deflect the laser beam off two mirrors and through some optics (often an f-theta lens) to focus the beam to a $0.05 \mathrm{~mm}$ to $0.5 \mathrm{~mm}$ beam width on the top surface of the powder bed. The beam is scanned by a galvanometer system that rotates the deflecting mirrors. Laser scan speeds can be as fast as $7 \mathrm{~m} / \mathrm{s}$. Parts are typically built by first tracing the laser spot over the perimeter of the layer's geometry, then filling the area with a raster or hatch pattern.

Table 1. Summary of the research efforts applicable to AM PBF and related non-PBF control schemes

\begin{tabular}{|c|c|c|c|c|}
\hline \multicolumn{5}{|l|}{ PBF related } \\
\hline $\begin{array}{l}\text { Control } \\
\text { parameter }\end{array}$ & Setup & Correlations & Control & Reference \\
\hline Melt-pool size & $\begin{array}{l}\text { CMOS camera and } \\
\text { planar photodiode } \\
\text { coaxial with the laser }\end{array}$ & $\begin{array}{l}\text { Photodiode signal intensity and } \\
\text { melt-pool area. Melt-pool } \\
\text { dimensions as a function of X, Y } \\
\text { and positions of laser beam on the } \\
\text { X-Y plane }\end{array}$ & $\begin{array}{l}\text { Area-based signature as } \\
\text { feedback to control the laser } \\
\text { power }\end{array}$ & {$[6]-[8]$} \\
\hline $\begin{array}{l}\text { Surface } \\
\text { roughness of } \\
\text { solidified melt- } \\
\text { pool }\end{array}$ & $\begin{array}{l}\text { Pulsed laser system, } \\
\text { video camera }\end{array}$ & $\begin{array}{l}\text { Heat intensity and surface } \\
\text { roughness. } \\
\text { Pulse shapes and material spatter }\end{array}$ & Investigative & [9] \\
\hline Part geometry & $\begin{array}{l}\text { CMM, beam } \\
\text { compensation }\end{array}$ & $\begin{array}{l}\text { Shrinkage due to different } \\
\text { geometric shapes }\end{array}$ & $\begin{array}{l}\text { Laser beam, laser power and } \\
\text { scanning speed }\end{array}$ & $\begin{array}{l}{[10],[12],} \\
{[13]}\end{array}$ \\
\hline \multicolumn{5}{|c|}{ Non-PBF related } \\
\hline $\begin{array}{l}\text { Control } \\
\text { parameter }\end{array}$ & Setup & Correlations & & Reference \\
\hline $\begin{array}{l}\text { Bead profile } \\
\text { geometry }\end{array}$ & $\begin{array}{l}\text { Laser optical scanner, } \\
\text { IR pyrometer }\end{array}$ & $\begin{array}{l}\text { Input parameters and the bead } \\
\text { profile }\end{array}$ & $\begin{array}{l}\text { Control bead cross sectional } \\
\text { area and with a single process } \\
\text { input parameter along with the } \\
\text { inverse source velocity }\end{array}$ & {$[14]$} \\
\hline Part geometry & $\begin{array}{l}\text { FDM and } \\
\text { compensation } \\
\text { algorithm } \\
\end{array}$ & $\begin{array}{l}\text { Geometric measurements and a } \\
\text { model of the target object }\end{array}$ & $\begin{array}{l}\text { Compensation droplets to } \\
\text { match the target geometry }\end{array}$ & [20] \\
\hline $\begin{array}{l}\text { IR-temperature } \\
\text { signal }\end{array}$ & $\begin{array}{l}\text { PID-controller was } \\
\text { built between a Ge- } \\
\text { photodiode and laser }\end{array}$ & $\begin{array}{l}\text { Laser path versus homogeneity of } \\
\text { the microstructure, hardness, and } \\
\text { dimensional accuracy }\end{array}$ & $\begin{array}{l}\text { Process control with constant } \\
\text { set-values and laser path- } \\
\text { dependent set-values }\end{array}$ & {$[21],[25]$} \\
\hline $\begin{array}{l}\text { Delivered } \\
\text { powder volume }\end{array}$ & $\begin{array}{l}\text { Optoelectronic sensor } \\
\text { for powder delivery }\end{array}$ & $\begin{array}{l}\text { Thermal variation and processing } \\
\text { quality }\end{array}$ & $\begin{array}{l}\text { Controllable powder delivery } \\
\text { and heat input }\end{array}$ & {$[22],[23]$} \\
\hline Melt-pool size & $\begin{array}{l}\text { Thermal imaging, } \\
\text { process maps }\end{array}$ & $\begin{array}{l}\text { Transient behavior of melt-pool } \\
\text { size and laser power or velocity }\end{array}$ & $\begin{array}{l}\text { Dynamic feedback for desired } \\
\text { melt-pool size }\end{array}$ & $\begin{array}{l}{[15]-[19],} \\
{[24],[26]-} \\
{[28]}\end{array}$ \\
\hline
\end{tabular}


Table 2. Research on in-process measurement

\begin{tabular}{|c|c|c|}
\hline Purpose of in-process measurement & Measurement setup & Reference \\
\hline Surface temperature measurement & IR thermography and pyrometry, emissivity reference & $\begin{array}{l}{[8],[44]-} \\
{[63]}\end{array}$ \\
\hline $\begin{array}{l}\text { Correlate deviations of process signatures to input } \\
\text { parameters }\end{array}$ & Bi-color pyrometer & [63] \\
\hline $\begin{array}{l}\text { Determine temperature and time history of } \\
\text { temperature distribution in melt-pool area }\end{array}$ & Co-axial measurement system uses a bi-color pyrometer & [45] \\
\hline Determine melt-pool size and temperature & Photodiode and CMOS & [57] \\
\hline $\begin{array}{l}\text { Use temperature maps to detect deformation due to } \\
\text { thermal stresses and overheating zones due to } \\
\text { overhangs }\end{array}$ & $\begin{array}{l}\text { Co-axial near-IR ( } 780 \mathrm{~nm} \text { to } 950 \mathrm{~nm}) \text { temperature } \\
\text { measurement system consisting of a planar (?) } \\
\text { photodiode and a high-speed CMOS camera. }\end{array}$ & [8] \\
\hline $\begin{array}{l}\text { Monitor beam-powder interaction, quantify beam } \\
\text { focus size, and detect porosity }\end{array}$ & IR-thermography imaging system & {$[60]$} \\
\hline $\begin{array}{l}\text { Monitor melt-pool dynamics by introducing } \\
\text { additional illumination source for high resolution } \\
\text { imaging at high scanning velocities }\end{array}$ & Co-axial optical system & {$[47]$} \\
\hline $\begin{array}{l}\text { Measure the melt-pool size as well as the } \\
\text { temperature profile across the melt-pool }\end{array}$ & $\begin{array}{l}\text { Near- IR }(780 \text { to } 1080 \mathrm{~nm}) \text { thermography (with } 60 \mathrm{~Hz} \\
\text { frame rate) }\end{array}$ & {$[62]$} \\
\hline Track movement of heat through the laser track & Thermography-based system & [59] \\
\hline Strain measurement & $\begin{array}{l}\text { Surface distortion measurement, strain gages mounted to } \\
\text { the build platform }\end{array}$ & $\begin{array}{l}{[64]-} \\
{[68][70],[71]}\end{array}$ \\
\hline Geometric measurements & Vision system & {$[72]-[74]$} \\
\hline
\end{tabular}

Table 3. Dimensional accuracy research summary

\begin{tabular}{|c|c|c|c|c|}
\hline Purpose & Variables & Instruments & Correlations & Reference \\
\hline $\begin{array}{l}\text { Evaluate SLM of low } \\
\text { cost powders }\end{array}$ & $\begin{array}{l}\text { Layer thickness. } \\
\text { Laser scanning } \\
\text { speed }\end{array}$ & $\begin{array}{l}\text { Renishaw Cyclone II 3D } \\
\text { scanner (scan probe) }\end{array}$ & $\begin{array}{l}\text { Measured dimensions before } \\
\text { finishing were } 2-4 \% \text { larger than } \\
\text { designed, after finishing } \\
\text { dimensions were } 1.5 \% \text { larger, } \\
\text { tolerances were not uniform and } \\
\text { varied in the z-direction, no } \\
\text { shrinkage }\end{array}$ & [76] \\
\hline $\begin{array}{l}\text { Investigate elevated } \\
\text { edges }\end{array}$ & $\begin{array}{l}\text { Laser power, } \\
\text { speed, and scan } \\
\text { strategy, edge } \\
\text { height }\end{array}$ & $\begin{array}{l}\text { Contact surface profilometer, } \\
\text { optical microscope }\end{array}$ & $\begin{array}{l}\text { Not possible to eliminate the built } \\
\text { up edge, however, appropriate } \\
\text { process parameters and scanning } \\
\text { strategies can improve flatness }\end{array}$ & [75] \\
\hline $\begin{array}{l}\text { Influence of process } \\
\text { parameters on } \\
\text { dimensional accuracy }\end{array}$ & $\begin{array}{l}\text { Laser power, } \\
\text { speed, scan } \\
\text { strategy, layer } \\
\text { thickness }\end{array}$ & Profilometer, CMM & $\begin{array}{l}\text { Dimensional errors and control can } \\
\text { be specific geometric profiles }\end{array}$ & [13] \\
\hline $\begin{array}{l}\text { Analysis of the laser } \\
\text { energy required for } \\
\text { manufacturing }\end{array}$ & $\begin{array}{l}\text { Part geometry, } \\
\text { slice thickness } \\
\text { and the build } \\
\text { orientation }\end{array}$ & Mathematical analysis & $\begin{array}{l}\text { Laser energy expenditure of SLS } \\
\text { process and its correlation to the } \\
\text { geometry }\end{array}$ & [77] \\
\hline $\begin{array}{l}\text { Design of metal parts } \\
\text { fabricated by PBF }\end{array}$ & $\begin{array}{l}\text { Laser power, } \\
\text { speed, scan } \\
\text { strategy, layer } \\
\text { thickness, }\end{array}$ & CMM & $\begin{array}{l}\text { Process parameters and the } \\
\text { accuracy of the laser scanning units } \\
\text { were crucial to improve the } \\
\text { dimensional accuracy }\end{array}$ & [78] \\
\hline $\begin{array}{l}\text { Investigate } \\
\text { deformations and } \\
\text { deviations of } \\
\text { geometry of thin } \\
\text { walls in SLM }\end{array}$ & $\begin{array}{l}\text { Size and } \\
\text { position }\end{array}$ & CMM & $\begin{array}{l}\text { Deviations ranged from } 0.002 \mathrm{~mm} \\
\text { to } 0.202 \mathrm{~mm} \text { for position and size, } \\
\text { respectively }\end{array}$ & [79] \\
\hline
\end{tabular}




\begin{tabular}{|l|l|l|l|l|}
\hline $\begin{array}{l}\text { Influence of process } \\
\text { parameters on part } \\
\text { quality }\end{array}$ & $\begin{array}{l}\text { Laser power, } \\
\text { speed, and scan } \\
\text { strategy }\end{array}$ & $\begin{array}{l}\text { X-ray spectroscopy, Scanning } \\
\text { Electron Microscope, Energy- } \\
\text { dispersive X-ray spectroscopy, } \\
\text { surface profilometer, universal } \\
\text { testing machine, hardness tester }\end{array}$ & $\begin{array}{l}\text { Build direction has a significant } \\
\text { effect on part quality, in terms of } \\
\text { dimensional error and surface } \\
\text { roughness. }\end{array}$ & $\begin{array}{l}\text { [80] } \\
\text { Quality optimization } \\
\text { of overhanging } \\
\text { surfaces }\end{array}$ \\
\hline
\end{tabular}

Table 4. Surface quality research summary

\begin{tabular}{|c|c|c|c|c|}
\hline Purpose & Variables & Instruments & Correlations & Reference \\
\hline $\begin{array}{l}\text { Evaluate SLM of } \\
\text { low cost powders }\end{array}$ & Roughness & $\begin{array}{l}\text { High sensitivity } \\
\text { digital scale, } \\
\text { Renishaw Cyclone II } \\
\text { 3D scanner, SEM, } \\
\text { JOEL JSM5200, } \\
\text { EDX analyzer }\end{array}$ & $\begin{array}{l}\text { Large particles inside thick layers } \\
\text { increased surface roughness. Side } \\
\text { surface was smoother at the bottom } \\
\text { than at the top }\end{array}$ & [76] \\
\hline $\begin{array}{l}\text { Investigate pulse } \\
\text { shaping on SLM } \\
\text { of thin walled } \\
\text { parts }\end{array}$ & $\begin{array}{l}\text { Pulse shape, roughness, } \\
\text { width, degree of plasma } \\
\text { plume }\end{array}$ & $\begin{array}{l}\text { Profilometer, digital } \\
\text { calipers, digital video } \\
\text { camera }\end{array}$ & $\begin{array}{l}\text { Pulse shaping was shown to reduce } \\
\text { spatter ejection, improve top surface } \\
\text { roughness, and minimize melt-pool } \\
\text { width }\end{array}$ & [9] \\
\hline $\begin{array}{l}\text { Investigate } \\
\text { failures }\end{array}$ & $\begin{array}{l}\text { Layer thickness, scanning } \\
\text { speed, orientation, energy } \\
\text { density, part density and } \\
\text { roughness }\end{array}$ & SEM & $\begin{array}{l}\text { A narrow processing window exists } \\
\text { that produces } 100 \% \text { part density and } \\
\text { the best surface quality }\end{array}$ & [82] \\
\hline $\begin{array}{l}\text { Investigate } \\
\text { elevated edges }\end{array}$ & $\begin{array}{l}\text { Laser power, speed, and } \\
\text { scan strategy, edge height }\end{array}$ & $\begin{array}{l}\text { Contact surface } \\
\text { profilometer, optical } \\
\text { microscope }\end{array}$ & $\begin{array}{l}\text { Edge height ranged from } 10 \text { um to } \\
160 \mu \mathrm{m} \text {, not possible to eliminate the } \\
\text { built up edge, however, appropriate } \\
\text { process parameters and scanning } \\
\text { strategies can improve flatness }\end{array}$ & {$[75]$} \\
\hline $\begin{array}{l}\text { Influence of } \\
\text { particle size } \\
\text { distribution on } \\
\text { surface quality } \\
\text { and properties }\end{array}$ & $\begin{array}{l}\text { Particle size, layer } \\
\text { thickness }\end{array}$ & Mechanical testing & $\begin{array}{l}\text { Optimized powder granulations } \\
\text { generally lead to improved } \\
\text { mechanical properties }\end{array}$ & [42] \\
\hline $\begin{array}{l}\text { Influence of } \\
\text { process } \\
\text { parameters on } \\
\text { part quality }\end{array}$ & $\begin{array}{l}\text { Scanning speed, layer } \\
\text { thickness, and building } \\
\text { direction }\end{array}$ & $\begin{array}{l}\text { X-ray spectroscopy, } \\
\text { Scanning Electron } \\
\text { Microscope, Energy- } \\
\text { dispersive X-ray } \\
\text { spectroscopy, surface } \\
\text { profilometer, } \\
\text { universal testing } \\
\text { machine, hardness } \\
\text { tester }\end{array}$ & $\begin{array}{l}\text { Mechanical properties } \\
\text { and surface finish sensitive to the } \\
\text { build direction and layer } \\
\text { thickness }\end{array}$ & [80] \\
\hline
\end{tabular}


Table 5. Mechanical properties research summary

\begin{tabular}{|c|c|c|c|c|}
\hline Purpose & Variables & Instruments & Correlations & Reference \\
\hline Investigate failures & $\begin{array}{l}\text { Layer thickness, } \\
\text { scanning speed, } \\
\text { orientation, } \\
\text { energy density, } \\
\text { part density and } \\
\text { roughness }\end{array}$ & SEM & $\begin{array}{l}\text { Density measurements do not } \\
\text { identify deficient connections of } \\
\text { consecutive layers, vertically } \\
\text { fabricated specimens have lower } \\
\text { tensile strengths and elongations }\end{array}$ & {$[82]$} \\
\hline $\begin{array}{l}\text { Evaluate PBF of low } \\
\text { cost powders }\end{array}$ & $\begin{array}{l}\text { Layer thickness, } \\
\text { scan speed }\end{array}$ & $\begin{array}{l}\text { Vickers \& Micro-vickers, } \\
\text { stress-strain }\end{array}$ & $\begin{array}{l}\text { Hardness not as affected by the } \\
\text { parameters, however, variations } \\
\text { due to surface porosity were } \\
\text { observed. Strength was best at } \\
\text { low speeds and thickness. Part } \\
\text { became brittle with higher layer } \\
\text { thickness due to porosity and } \\
\text { micro-cracking. }\end{array}$ & {$[76]$} \\
\hline $\begin{array}{l}\text { Investigate dynamic } \\
\text { strength and fracture } \\
\text { toughness on a } \\
\text { cylindrical beam and } \\
\text { disk }\end{array}$ & $\begin{array}{l}\text { Standard exposure } \\
\text { strategies }\end{array}$ & Rotating bending fatigue tests & $\begin{array}{l}\text { Fatigue strength was comparable } \\
\text { to conventionally manufactured } \\
\text { parts }\end{array}$ & {$[83]$} \\
\hline $\begin{array}{l}\text { Qualifying metal based } \\
\text { powder systems for } \\
\text { automotive }\end{array}$ & $\begin{array}{l}\text { Build orientation, } \\
\text { surface finish, } \\
\text { temperature }\end{array}$ & $\begin{array}{l}\text { Material analysis, } \\
\text { Tensile test, compression test }\end{array}$ & $\begin{array}{l}\text { Material properties are sensitive } \\
\text { to the build direction. Surface } \\
\text { treatment potential method to } \\
\text { increase material properties. } \\
\text { Materials strength decreases } \\
\text { with higher temperatures }\end{array}$ & {$[84]$} \\
\hline $\begin{array}{l}\text { Study on material } \\
\text { properties and process } \\
\text { parameters }\end{array}$ & $\begin{array}{l}\text { Material } \\
\text { properties }\end{array}$ & $\begin{array}{l}\text { Material analysis, } \\
\text { Tensile test }\end{array}$ & $\begin{array}{l}\text { Powder properties directly affect } \\
\text { the process in turn affect the } \\
\text { mechanical properties }\end{array}$ & {$[85]$} \\
\hline $\begin{array}{l}\text { Correlation of process } \\
\text { parameters and part } \\
\text { properties in laser } \\
\text { sintering }\end{array}$ & $\begin{array}{l}\text { Laser power, scan } \\
\text { spacing, scan } \\
\text { speed, powder } \\
\text { bed temperature, } \\
\text { layer thickness, } \\
\text { energy density } \\
\end{array}$ & Tensile test & $\begin{array}{l}\text { Four main influences on } \\
\text { mechanical properties were } \\
\text { scan spacing, scan speed, layer } \\
\text { thickness, and interaction of } \\
\text { scan spacing and layer thickness }\end{array}$ & {$[86]$} \\
\hline $\begin{array}{l}\text { Characterization of a } \\
\text { Commercial AlSiMg } \\
\text { Alloy Processed } \\
\text { through Direct Metal } \\
\text { Laser Sintering }\end{array}$ & Build orientations & $\begin{array}{l}\text { Light microscopy; electron } \\
\text { microscopy }\end{array}$ & $\begin{array}{l}\text { Difference in mechanical and } \\
\text { microstructural properties of } \\
\text { specimens built along different } \\
\text { orientations }\end{array}$ & [87] \\
\hline $\begin{array}{l}\text { Investigate single layer } \\
\text { track stability }\end{array}$ & $\begin{array}{l}\text { Powder input, } \\
\text { scanning speed, } \\
\text { laser power }\end{array}$ & $\begin{array}{l}\text { Optical granulomorphometer, } \\
\text { real-time optical sieving } \\
\text { system, image analysis } \\
\text { software }\end{array}$ & $\begin{array}{l}\text { Negative correlation is found } \\
\text { between the thermal } \\
\text { conductivity of bulk material } \\
\text { and the range of optimal } \\
\text { scanning speed for the } \\
\text { continuous single track sintering }\end{array}$ & {$[88]$} \\
\hline PBF of dies & Laser offset & $\begin{array}{l}\text { Single/ dual lasers, Vickers } \\
\text { hardness testing machine }\end{array}$ & $\begin{array}{l}\text { Vickers hardness decreases as } \\
\text { beam offset increases. Reheating } \\
\text { increases bending strength }\end{array}$ & {$[161]$} \\
\hline $\begin{array}{l}\text { Analyze the influence } \\
\text { of the manufacturing } \\
\text { strategy on the internal } \\
\text { structure and } \\
\text { mechanical properties } \\
\text { of the components }\end{array}$ & $\begin{array}{l}\text { Hatch distance, } \\
\text { build orientation }\end{array}$ & $\begin{array}{l}\text { Granulo-morphometer, } \\
\text { INSTRON }\end{array}$ & $\begin{array}{l}\text { Two-zone method created the } \\
\text { lowest porosity }<1 \% \text {, yield \& } \\
\text { ultimate tensile strength was } \\
\text { consistent with both vertical and } \\
\text { horizontal build directions, } \\
\text { Young's modulus is } 1.5 \text { times } \\
\text { higher for horizontal builds }\end{array}$ & [89] \\
\hline
\end{tabular}




\begin{tabular}{|c|c|c|c|c|}
\hline $\begin{array}{l}\text { Influence of particle } \\
\text { size distribution on } \\
\text { surface quality and } \\
\text { properties }\end{array}$ & $\begin{array}{l}\text { Particle size, layer } \\
\text { thickness }\end{array}$ & Mechanical testing & $\begin{array}{l}\text { Optimized powder granulations } \\
\text { generally lead to improved } \\
\text { mechanical properties }\end{array}$ & {$[42]$} \\
\hline $\begin{array}{l}\text { Effect of PBF layout on } \\
\text { quality }\end{array}$ & Gas flow direction & $\begin{array}{l}\text { Porosity measurements, } \\
\text { mechanical testing }\end{array}$ & $\begin{array}{l}\text { Gas temperature/flow effects } \\
\text { part quality }\end{array}$ & [95] \\
\hline $\begin{array}{l}\text { Influence of process } \\
\text { parameters on part } \\
\text { quality }\end{array}$ & $\begin{array}{l}\text { Scanning speed, } \\
\text { layer thickness, } \\
\text { and building } \\
\text { direction }\end{array}$ & $\begin{array}{l}\text { X-ray spectroscopy, Scanning } \\
\text { Electron Microscope, Energy- } \\
\text { dispersive X-ray spectroscopy, } \\
\text { surface profilometer, universal } \\
\text { testing machine, hardness } \\
\text { tester }\end{array}$ & $\begin{array}{l}\text { For SLM process, the build } \\
\text { direction has no influence on } \\
\text { mechanical properties }\end{array}$ & {$[80]$} \\
\hline $\begin{array}{l}\text { Designing material } \\
\text { properties locally, PBF }\end{array}$ & $\begin{array}{l}\text { Energy density, } \\
\text { modulus, yield } \\
\text { strength }\end{array}$ & Brinell test & $\begin{array}{l}\text { Hardness is influenced by the } \\
\text { pore structure }\end{array}$ & [105] \\
\hline $\begin{array}{l}\text { Effect of geometry on } \\
\text { shear modulus }\end{array}$ & $\begin{array}{l}\text { Pitch of the spring } \\
\text { as geometric } \\
\text { factor }\end{array}$ & Compression test & $\begin{array}{l}\text { Geometry has a major effect on } \\
\text { the produced mechanical } \\
\text { properties }\end{array}$ & [162] \\
\hline $\begin{array}{l}\text { Investigate the effects } \\
\text { of preheating on the } \\
\text { distortion of } \mathrm{Al} \text { parts }\end{array}$ & $\begin{array}{l}\text { Preheat } \\
\text { temperature }\end{array}$ & $\begin{array}{l}\text { 3D Optical measurement } \\
\text { system }\end{array}$ & $\begin{array}{l}\text { Hardness decreases with preheat } \\
\text { temperature }\end{array}$ & {$[90]$} \\
\hline
\end{tabular}

Table 6. Residual stress research summary

\begin{tabular}{|c|c|c|c|}
\hline Purpose & Variables & Correlations & Reference \\
\hline Measure residual stress & Laser scanning, heating & $\begin{array}{l}\text { Base plate heating, re-scanning, and heat treatment } \\
\text { reduced residual stress }\end{array}$ & {$[70]$} \\
\hline Residual stresses in PBF & $\begin{array}{l}\text { Material properties, sample } \\
\text { and substrate height, the laser } \\
\text { scanning strategy and heating } \\
\text { conditions }\end{array}$ & $\begin{array}{l}\text { Heat treating, re-scanning, and heating of the base } \\
\text { plate helps relieve residual stress }\end{array}$ & [96] \\
\hline $\begin{array}{l}\text { Effects of positioning } \\
\text { powders and thickness on } \\
\text { residual stresses }\end{array}$ & Position and thickness & $\begin{array}{l}\text { Stress magnitude decreased moving towards inner } \\
\text { layers. }\end{array}$ & [94] \\
\hline $\begin{array}{l}\text { Investigate heat treatment } \\
\text { of PBF components }\end{array}$ & Temperature and time & $\begin{array}{l}\text { The most promising heat treatment consisted of a } \\
\text { moderate cooling rate after solution treatment at } \\
1,055 \mathrm{C}\end{array}$ & [99] \\
\hline $\begin{array}{l}\text { Investigate fatigue and } \\
\text { crack growth of TiAl6V4 } \\
\text { PBF in the z-direction }\end{array}$ & Temperature, atmosphere & $\begin{array}{l}\text { Micron sized pores mainly affect fatigue strength, } \\
\text { residual stresses have a strong impact on fatigue } \\
\text { crack growth }\end{array}$ & {$[93]$} \\
\hline $\begin{array}{l}\text { Investigate residual stress } \\
\text { and density }\end{array}$ & Laser power, heating & $\begin{array}{l}\text { Observed deformation was due to residual stress. } \\
\text { Stresses were found to be very high and approached } \\
\text { and exceeded the yield strength }\end{array}$ & [101] \\
\hline $\begin{array}{l}\text { Effect of PBF layout on } \\
\text { quality }\end{array}$ & Gas flow direction & Gas temperature/flow effects part quality & {$[95]$} \\
\hline $\begin{array}{l}\text { Investigate heat treatment } \\
\text { on residual stress, tensile } \\
\text { strength, and fatigue of } \\
\text { SLM components }\end{array}$ & $\begin{array}{l}\text { Temperature, time, gas, and } \\
\text { hot isostatic pressing }\end{array}$ & $\begin{array}{l}\text { Heat treating reduced residual and tensile stress and } \\
\text { increased fatigue life }\end{array}$ & [102] \\
\hline $\begin{array}{l}\text { Investigate the influence of } \\
\text { material properties son } \\
\text { residual stress }\end{array}$ & $\begin{array}{l}\text { Density, micro hardness, } \\
\text { curl-up angle }\end{array}$ & $\begin{array}{l}\text { Micro-cracking and the formation of oxides effect } \\
\text { residual stress, material properties influence was } \\
\text { obscured }\end{array}$ & [97] \\
\hline $\begin{array}{l}\text { Measure residual stress to } \\
\text { validate numerical model }\end{array}$ & $\begin{array}{l}\text { Strain, temperature, cooling } \\
\text { time }\end{array}$ & $\begin{array}{l}\text { Residual stresses are largest for large layer } \\
\text { thickness }(5 \mathrm{~mm}) \text { and long cooling time. }\end{array}$ & {$[71],[94]$} \\
\hline
\end{tabular}




\begin{tabular}{|l|l|l|l|}
\hline $\begin{array}{l}\text { Investigate the effects of } \\
\text { preheating on the distortion } \\
\text { of Al parts }\end{array}$ & Preheat temperature & $\begin{array}{l}\text { Reduction in distortion begins at a preheat } \\
\text { temperature of 150 C, distortion is no longer } \\
\text { observed at a preheat temperature 250 C and above, } \\
\text { additionally, hardness decreases with preheat } \\
\text { temperature }\end{array}$ & {$[90]$} \\
\hline
\end{tabular}

Table 7. Porosity/density research summary

\begin{tabular}{|c|c|c|c|}
\hline Purpose & Variables & Correlations & Reference \\
\hline $\begin{array}{l}\text { Comparison of density of } \\
316 \mathrm{~L}\end{array}$ & $\begin{array}{l}\text { layer thickness, particle } \\
\text { size, distribution, Mettler } \\
\text { balance }\end{array}$ & Basic powder requirements identified & [41] \\
\hline Study PBF & $\begin{array}{l}\text { Layer thickness, scanning } \\
\text { speed, orientation, energy } \\
\text { density, part density and } \\
\text { roughness }\end{array}$ & $\begin{array}{l}\text { Density measurements do not identify deficient } \\
\text { connections of consecutive layers, a narrow } \\
\text { processing window (energy density) exists that } \\
\text { produces } 100 \% \text { part density and the best surface } \\
\text { quality }\end{array}$ & {$[82]$} \\
\hline $\begin{array}{l}\text { Investigate the effects of } \\
\text { re-melting on density }\end{array}$ & $\begin{array}{l}\text { Scan speed, scan spacing, } \\
\text { pulse frequency }\end{array}$ & $\begin{array}{l}\text { Increase density with decreasing scan speed, density } \\
\text { decreases with decreasing scan spacing (although not } \\
\text { significant }\end{array}$ & [103] \\
\hline $\begin{array}{l}\text { Investigate the influence } \\
\text { of laser remelting on } \\
\text { density }\end{array}$ & $\begin{array}{l}\text { Scan spacing, scan speed, } \\
\text { number of re-melting scans, } \\
\text { laser power }\end{array}$ & $\begin{array}{l}\text { Higher re-melting scan speed with low laser power } \\
\text { exhibits very-low-porosity, additional re-melting did } \\
\text { not significantly change porosity. Increased energy by } \\
\text { decreasing the scan spacing and increasing the } \\
\text { number of scans increased porosity, but not as bad as } \\
\text { not remelting }\end{array}$ & [104] \\
\hline $\begin{array}{l}\text { Designing material } \\
\text { properties locally in PBF } \\
\text { process }\end{array}$ & $\begin{array}{l}\text { Build orientation, layer } \\
\text { thickness, scan speed, laser } \\
\text { power, heat treat, energy } \\
\text { density }\end{array}$ & $\begin{array}{l}\text { Generated a curve for density as a function of specific } \\
\text { energy input, Boccaccini equation can be used to } \\
\text { predict modulus as a function of porosity, hardness is } \\
\text { influenced by the pore structure }\end{array}$ & {$[105]$} \\
\hline $\begin{array}{l}\text { Investigate the density of } \\
\text { PBF powders: gas } \\
\text { atomized and water } \\
\text { atomized }\end{array}$ & $\begin{array}{l}\text { Particle size, shape, and } \\
\text { distribution }\end{array}$ & $\begin{array}{l}\text { Lower laser power, higher scan speed, and thicker } \\
\text { layer yields worsened wetting characteristic } \\
\text { characterized by fluctuant surface, gas atomized } \\
\text { powder produces denser structures, pore size } \\
\text { increased with increase hatch spacing }\end{array}$ & {$[106]$} \\
\hline $\begin{array}{l}\text { Influences of energy } \\
\text { density on porosity and } \\
\text { microstructure of PBF 17- } \\
\text { 4PH }\end{array}$ & $\begin{array}{l}\text { Layer thickness, scanning } \\
\text { speed, orientation, energy } \\
\text { density, part density and } \\
\text { roughness }\end{array}$ & $\begin{array}{l}\text { Energy density may not be a good indicator for } \\
\text { porosity level of SLM manufactured parts. Balling } \\
\text { phenomena and high thermal stress cracking are } \\
\text { mainly responsible for the porosity }\end{array}$ & [107],[108] \\
\hline $\begin{array}{l}\text { Effects of the variation of } \\
\text { sintering parameters }\end{array}$ & $\begin{array}{l}\text { Layer thickness and } \\
\text { hatching distance }\end{array}$ & $\begin{array}{l}\text { Increasing layer thickness and hatching distance } \\
\text { results in an increase in porosity that diminishes the } \\
\text { hardness and density }\end{array}$ & {$[109]$} \\
\hline AM tool comparison & $\begin{array}{l}\text { Manufacturers recipe, } \\
\text { processing cost, optical } \\
\text { emission spectrometer }\end{array}$ & $\begin{array}{l}\text { Density ranged from } 82.6 \% \text { to } 99.23 \%, \text { SLS } \\
\text { produced the best density }\end{array}$ & {$[110]$} \\
\hline $\begin{array}{l}\text { Study the influence of the } \\
\text { hatch distance on internal } \\
\text { structure and porosity }\end{array}$ & $\begin{array}{l}\text { Hatch distance, build } \\
\text { orientation }\end{array}$ & $\begin{array}{l}\text { Porosity increased as hatch distance increased, two- } \\
\text { zone method created the lowest porosity }<1 \% \text {, yield } \\
\& \text { ultimate tensile strength was consistent with both } \\
\text { vertical and horizontal build directions, Young's } \\
\text { modulus is } 1.5 \text { times higher for horizontal builds }\end{array}$ & [89] \\
\hline $\begin{array}{l}\text { Investigate residual stress } \\
\text { in PBF }\end{array}$ & Specimen thickness & Produced parts with $1.4 \%$ porosity & {$[163]$} \\
\hline $\begin{array}{l}\text { Investigate increased } \\
\text { production with increased } \\
\text { laser power }\end{array}$ & Laser power, scan speed & $\begin{array}{l}\text { With } 1 \mathrm{KW} \text { lasers scan speed, scan spacing, and build } \\
\text { rate can be significantly increased }\end{array}$ & {$[164]$} \\
\hline Reduce required laser & Hatch distance, scan speed & Low scan speeds generate roughness greater than the & {$[165]$} \\
\hline
\end{tabular}




\begin{tabular}{|c|c|c|c|}
\hline $\begin{array}{l}\text { power and increase scan } \\
\text { rate by investigating their } \\
\text { effects on porosity }\end{array}$ & & $\begin{array}{l}\text { set layer thickness, high scan speeds led to lower } \\
\text { relative densities due to insufficient powder melting }\end{array}$ & \\
\hline $\begin{array}{l}\text { Comparison of density } \\
\text { measurement techniques }\end{array}$ & Particle size, layer thickness & $\begin{array}{l}\text { Porosity is less controllable at high scan speeds, } \\
\text { Archimedes method has lower uncertainty and greater } \\
\text { repeatability }\end{array}$ & {$[42]$} \\
\hline $\begin{array}{l}\text { To investigate the } \\
\text { influence of volume } \\
\text { energy density on } \\
\text { porosity }\end{array}$ & $\begin{array}{l}\text { Laser power, scan speed, } \\
\text { hatching distance, layer } \\
\text { thickness, }\end{array}$ & $\begin{array}{l}\text { The volume energy density, including all four } \\
\text { investigated parameters, shows a strong } \\
\text { influence on the overall porosity }\end{array}$ & {$[111]$} \\
\hline $\begin{array}{l}\text { Evaluate PBF of low cost } \\
\text { powders }\end{array}$ & $\begin{array}{l}\text { Part geometry, dimensional } \\
\text { tolerance, surface quality, } \\
\text { density, mechanical } \\
\text { properties and } \\
\text { microstructure }\end{array}$ & $\begin{array}{l}\text { Density decreased at larger layer thickness, smaller } \\
\text { particles increased density, lower scan speeds } \\
\text { increase melting and reduced surface tension of the } \\
\text { melt-pool }\end{array}$ & {$[76]$} \\
\hline $\begin{array}{l}\text { Investigate density and } \\
\text { residual stress within PBF } \\
\text { specimens }\end{array}$ & Laser power, heating & $\begin{array}{l}\text { Archimedes-method yielded an average density of } \\
99.75 \% \text { and pixel analysis yielded an avg. of } 99.7 \% \text {. } \\
\text { Sharp-edged defects and near circular voids existed. } \\
\text { SLM can produce near full dense parts }\end{array}$ & {$[101]$} \\
\hline
\end{tabular}

Table 8. Fatigue related research summary

\begin{tabular}{|l|l|l|l|}
\hline Purpose & Variables & Correlations & Reference \\
\hline $\begin{array}{l}\text { Investigate dynamic strength and } \\
\text { fracture toughness }\end{array}$ & $\begin{array}{l}\text { Standard exposure } \\
\text { strategies }\end{array}$ & $\begin{array}{l}\text { SLM fatigue strength comparable to } \\
\text { conventional manufactured parts }\end{array}$ & [83] \\
\hline $\begin{array}{l}\text { Investigate fatigue and crack growth } \\
\text { of TiAl6V4 PBF in the z-direction }\end{array}$ & Temperature, atmosphere & $\begin{array}{l}\text { Micron sized pores mainly affect fatigue } \\
\text { strength, residual stresses have a strong impact } \\
\text { on fatigue crack growth }\end{array}$ & [93] \\
\hline Functional parts for formula race car & Static and dynamic stress & $\begin{array}{l}\text { Parts can be manufactured with SLM, brackets } \\
\text { survived a year of racing }\end{array}$ & [42] \\
\hline $\begin{array}{l}\text { Investigate microstructure, high } \\
\text { cycle fatigue, and fracture behavior } \\
\text { of PBF samples }\end{array}$ & $\begin{array}{l}\text { Build platform } \\
\text { temperature, vertical } \\
\text { build orientation, and } \\
\text { heat treat }\end{array}$ & $\begin{array}{l}\text { effect and the building direction has the least } \\
\text { on fatigue. Fatigue of samples is higher than } \\
\text { standard DIN EN 1706 }\end{array}$ & [112] \\
\hline $\begin{array}{l}\text { Investigate and compare fatigue } \\
\text { performance PBF stainless steel } \\
\text { parts to conventionally processed } \\
\text { materials }\end{array}$ & Static and dynamic stress & $\begin{array}{l}\text { As fabricated were the weakest, polished was } \\
\text { slightly better than machined }\end{array}$ & [115] \\
\hline $\begin{array}{l}\text { Fatigue performance of Ti-6Al-4V } \\
\text { Roughness }\end{array}$ & $\begin{array}{l}\text { Remperature, vertical/ } \\
\text { orientation, and heat treat }\end{array}$ & $\begin{array}{l}\text { Horizontally built samples showed relatively } \\
\text { better tensile properties as compared with the } \\
\text { vertically built samples }\end{array}$ & [113] \\
\hline Fatigue performance of PBF parts & [117] \\
\hline
\end{tabular}

